\title{
Relational Contracts and Supplier Turnover in the Global Economy
}

\author{
Fabrice Defever*
}

\author{
Christian Fischer ${ }^{\dagger}$
}

Jens Suedekum ${ }^{\ddagger}$

August 4, 2016

\begin{abstract}
Headquarters and their specialized component suppliers have a vital interest in establishing long-term collaborations. When formal contracts are not enforceable, such efficiencyenhancing cooperations can be established via informal agreements, but relational contracts have been largely ignored in the literature on the international organization of value chains. In this paper, we develop a dynamic property rights model of global sourcing. A domestic headquarter collaborates with a foreign input supplier and makes two decisions in every period: i) whether to engage in a costly search for a better partner, and ii) whether to make a non-binding offer to overcome hold-up problems. Our key result is that the possibility to switch partners crucially affects the contractual nature of buyer-supplier relationships. In particular, some patient firms do not immediately establish a relational contract, but only when they decide to stop searching and thus launch a long-term collaboration with their supplier. Using firm-product-level data of fresh Chinese exporters to the US, we obtain empirical evidence in line with the predictions of our theory.
\end{abstract}

Keywords: Firm organization, input sourcing, relational contracts, supplier search.

JEL-class.: F23, D23, L23

\footnotetext{
*University of Nottingham, GEP, CESifo and CEP. Email: fabrice.defever@nottingham.ac.uk

$\dagger^{\dagger}$ Düsseldorf Institute for Competition Economics (DICE), Heinrich-Heine-Universität Düsseldorf, Germany. Email: fischer@dice.hhu.de

${ }^{\ddagger}$ Düsseldorf Institute for Competition Economics (DICE), Heinrich-Heine-Universität Düsseldorf, Germany, and CEPR. Email: suedekum@dice.hhu.de
}

The authors thank Stephen Yeaple (the editor), two anonymous referees, Pol Antràs, Jonathan Eaton, Hartmut Egger, Gabriel Felbermayr, Willi Kohler, Kalina Manova, Michael Pflüger, Andrei Potlogea, John Ries, Frederic Robert-Nicoud, Esteban Rossi-Hansberg, Deborah Swenson, Olga Timoshenko, Jo van Biesebroeck, Frank Verboven and various seminar audiences for helpful comments and suggestions. All errors are our responsibility. Suedekum acknowledges financial support by the German National Science Foundation (DFG), grant SU-413/2-1. 


\section{Introduction}

Intermediate inputs account for a substantial share of global trade. A large chunk of this trade involves a buyer - often a large and powerful headquarter firm located in a highincome country - who imports components from a foreign supplier (Johnson and Noguera, 2012). These suppliers are often located in low-wage countries with relatively unfamiliar market conditions and weak legal institutions, and it is well documented (see, e.g., Egan and Mody, 1992) that economic exchange in such environments is hampered by two main problems: search and contractual frictions. First, the buyer needs to find a supplier who is technologically capable of producing the desired input in appropriate quantity and quality and at low costs. Second, it wants to make sure that this supplier does not behave opportunistically, frequently renege on the agreed terms, engage in haggling, and so on. Finding such an efficient and reliable partner is costly and can involve a time consuming trial-and-error process before the firm is finally satisfied with the match.

How can hold-up problems and the resulting inefficiencies be alleviated when formal contracts are not enforceable? The theory of the firm, especially the work by Baker, Gibbons and Murphy (2002), suggests that relational contracts (RC) play an important role. These are purely informal and trust-based agreements to cooperate in an enduring relationship. And indeed, various management studies show that headquarter corporations and specialized component manufacturers have a vital interest in establishing and maintaining long-term collaborations in order to create and to share relational rents. The previous economics literature on the international organization of value chains has so far largely ignored relational agreements, however, and how they might resolve underinvestment problems in the context of input sourcing. Our model builds on the seminal property rights theory along the lines of Grossman and Hart (1986) and Hart and Moore (1990), which has been embodied in an international trade context by Antràs (2003) and Antràs and Helpman (2004), and places this into a dynamic setting with repeated interactions. Moreover, our framework allows for supplier re-matching subject to a search friction, since firms in practice can terminate collaborations if they are not satisfied or if the current partner does not behave cooperatively. We endogenously determine with whom and how the buyer interacts, and show that the possibility to switch partners crucially affects the contractual nature of buyer-supplier relationships.

Theory: In our dynamic model, there is a domestic headquarter firm that collaborates with a foreign supplier in an environment of incomplete contracts. The firm makes two decisions in every period. First, observing her current match, she decides whether to engage in a costly search for a better supplier. Second, she can offer a RC to her supplier, by promising him an ex post bonus payment if he reliably provides the input as stipulated in their agreement. Neither this bonus, nor the relationship-specific input investments are contractible. Yet, if agents are patient enough on average, an efficient long-term RC can be implemented in equilibrium that overcomes hold-up and underinvestment problems.

At first we study the firm's search for an efficient partner, who can provide the input of a given quality at lower unit costs. In the main text we make several assumptions to keep this analysis as simple as possible. For instance, we consider a grim trigger 
strategy in that repeated game setting, where a deviation is punished with infinite Nash reversion. Furthermore, we assume that the suppliers' unit costs are perfectly observable to the headquarter, that there are only two types of suppliers (with high and low unit costs, respectively), and that the producer must switch partners when she decides to pay the fixed re-matching cost. In a supplementary appendix, we generalize our model along all those lines. Specifically, we there consider an optimal punishment strategy as in Abreu (1988), imperfect monitoring as in the seminal collusion model by Green and Porter (1984), a continuous distribution from which the supplier's productivity is drawn (in a related fashion to Melitz, 2003), and similarly as in Burdett (1978), we separate the processes of search and re-matching by assuming that the firm may also stick to her current partner if she encounters a candidate that is less efficient than her current match. In a second step of our analysis, we then allow for heterogeneity in the time discount rate across potential suppliers and study the firm's search for a reliable partner. This analysis shows that for sufficiently low search costs the firm seeks to find a patient supplier, who tends to be more cooperative as he cares more about future profits.

Our model delivers a key insight whose essence remains robust in all variations and extensions: long-term collaborations (LTCs) and relational contracts (RCs) sharply need to be distinguished, but the two concepts are correlated. To see the first part, notice that if agents are too impatient, the firm may collaborate non-cooperatively with a supplier on a long-term basis, but they are never able to establish an efficient informal agreement. Hence, a LTC is not the same as a RC. On the second part, our model clarifies that an efficient $\mathrm{RC}$ is only feasible among patient agents, and it would surely emerge in equilibrium if supplier re-matching was ruled out. But once this realistic option is introduced, the firm only starts a $\mathrm{RC}$ once it is satisfied with the quality of her current supplier and decides to stop searching for a better partner. In other words, there is a positive correlation since the endogenous decision to launch a LTC can start the emergence of a RC.

This result adds a novel perspective to the literature on the international organization of value chains, and the theory of the firm more generally. The upshot of that literature is that sufficiently patient agents may overcome inefficiencies that bad legal institutions and weak contract enforcement may create. This insight also applies in the context of input sourcing, but our theory goes beyond this point. It explicates that the relevant decision with whom to interact is crucially important for the interrelated question how the contractual nature of this interaction will look like.

Empirical Application: While we mostly focus on the model, we also aim for an empirical application to address the practical relevance of this theoretical prediction. Putting our model to a test is challenging, however, because several key aspects are unobservable to the researcher. Our theory is about particular matches of domestic buyers and foreign suppliers, but current data only rarely allows observing such matches. ${ }^{1}$ Moreover, even

\footnotetext{
${ }^{1} \mathrm{~A}$ notable exception is the paper by Eaton et al. (2014) who are able to construct pairs of Colombian exporters and their US importers. They show that most exporters contract only with a single importing partner, thus suggesting that most trade is indeed relationship-specific. Moreover, they find considerable variation in relationship durations, pointing at a co-existence of one-shot and long-term collaborations in that market. Our model is consistent with both empirical features. More recent studies which also use proprietary Census data on matches of US importers and foreign exporters include Monarch (2015) and Kamal and Tang (2015).
} 
if they were known, we cannot observe the detailed explicit and implicit match-specific arrangements between the buyer and the supplier on which our model makes sharp predictions. Recent work by Macchiavello and Morjaria (2014) has addressed those problems by turning to a detailed case study for one specific industry (coffee beans in Rwanda), where firms are surveyed about their buyer-supplier arrangements.

In this paper, we adopt a different approach. We exploit Chinese customs data that encompass all exports to the US and other destination markets between 2000 and 2006 at the firm-product level. This context is thus fairly broad and well suited for our purpose, because the paradigm of incomplete contracts appears to be quite plausible when it comes to input sourcing from China (Antràs 2015). The cost we have to bear, however, is that we need to rely on coarser empirical proxies whether a particular buyer-supplier match involves a relational agreement, namely by specific categories of processing trade arrangements (Feenstra and Hanson, 2005) that resemble the features of RCs fairly closely.

In line with our theory, we robustly find a positive correlation between LTCs and RCs in the data. More specifically, the longer a fresh Chinese exporter sells a particular product to the US, the more likely this is done under those processing arrangements with strong relational elements. Furthermore, we also test another prediction of our model, namely that the degree of heterogeneity across potential suppliers negatively affects LTCs and RCs, because it increases the firm's incentive to search and therefore postpones the formation of an efficient long-term collaboration. We empirically confirm this prediction as we find that a more dispersed distribution of suppliers' unit values is negatively associated with observed match durations, and with the share of RCs at the product level.

Related literature: A first strand of related literature incorporates elements of search and matching into models of international trade, either referring to sales agents and distributors (Rauch 1999; Antràs and Costinot 2011) or to input suppliers as in our model (Rauch and Watson 2003; Carballo, Ottaviano and Volpe-Martincus 2013; Bernard, Moxnes and Ulltveit-Moe 2014). While some of those models also deal with relationship durations, they are mostly silent on contractual choices and relational agreements.

A second strand incorporates contractual choices into models of export dynamics, see Araujo, Mion and Ornelas (2016) and Aeberhardt, Buono and Fadinger (2014). In those frameworks, a domestic exporter matches with a foreign sales agent who might behave opportunistically, and once the firm has found a reliable partner, she increases exports at the intensive margin. This is consistent with empirical evidence by Rauch and Watson (2003) and Besedes (2008), who find that firms initially place small test orders when they first deal with a new supplier, and increase order volumes when they are satisfied. Like the other contributions, our model features such a pattern since it predicts increasing investments once a long-term relational agreement is established. We then differ in two main respects. First, while those papers focus on the exporter, we are mainly interested in the decisions of the importing firm. Second, we can explicitly distinguish long-term collaborations and relational agreements which is not possible in those models.

Third, our model adds to a literature which has studied theoretically and empirically how relational agreements can overcome hold-up problems in the context of firm organization and input sourcing. Examples includes Macchiavello and Morjaria (2014), Board 
(2011), or Corts and Singh (2004). The models by Kukharskyy (2016), Kukharskyy and Pflüger (2016), and Kamal and Tang (2015) are particularly closely related, as they are also based on Antràs (2003). However, none of them studies the interaction between RCs and supplier re-matching, but they focus on the ownership choice of integration versus outsourcing (from which we abstract) in a repeated game setup with a fixed partner.

Finally, this paper is related to a small literature on repeated games with heterogeneous time discount factors (Harrington 1989; Lehrer and Pauzner 1999; Haag and Lagunoff 2007). Our model applies some techniques of this literature to the context of global sourcing, which seems especially relevant since economic environments are usually more volatile in less developed countries, so that suppliers from those economies may be less patient than large domestic headquarter corporations. Moreover, from a conceptual point of view, our model seems to be the first to consider this heterogeneity in a setting where agents not only choose their strategy how to interact, but also with whom they play.

The rest of this paper is organized as follows. Section 2 present the basic model. In Section 3, we analyze RCs when supplier re-matching is still ruled out. We introduce this option in Section 4. Section 5 presents our empirical application. Section 6 concludes.

\section{The Model}

Our model is related to Antràs (2003) and Antràs and Helpman (2004) and extends this seminal framework to a dynamic setting with repeated interactions and supplier search and re-matching. We first characterize market demand and firm technology. There is a single firm producing a final good for which it faces the following iso-elastic demand:

$$
y=A p^{-\frac{1}{1-\alpha}}, \quad 0<\alpha<1, A>0
$$

where $y$ is quantity, $p$ is price, $A>0$ measures the demand level, and $\alpha \in(0,1)$ is a parameter that governs the demand elasticity $1 /(1-\alpha)$.

The production technology for the final output requires two inputs, $h$ and $m$, and has the following Cobb-Douglas specification:

$$
y=\left(\frac{h}{\eta}\right)^{\eta}\left(\frac{m}{1-\eta}\right)^{1-\eta}, \quad 0<\eta<1
$$

The firm's headquarter (called $H$ ) is located in the domestic country and provides the input $h$ herself. The parameter $\eta$ captures the headquarter-intensity of final good's production. The component $m$ is an intermediate input which is sourced from an independent foreign supplier (called $M){ }^{2}{ }^{2}$ We assume that $\mathrm{H}$ and $\mathrm{M}$ have constant marginal costs of input production, denoted respectively by $c_{h}$ and $c_{m}$, and face zero fixed costs. Moreover, $\tau>1$ units of the input $m$ need to be shipped for one unit to arrive in the domestic country. Finally, following Antràs (2003) and Antràs and Helpman (2004), we

\footnotetext{
${ }^{2}$ In this paper we do not analyze the integration versus outsourcing decision central to the Antràs (2003)model, but we assume that $M$ is an independent supplier with full ownership rights over his assets. Moreover, we assume that there is just one single intermediate input, and thus one supplier to contract with. See Schwarz and Suedekum (2014) for a (static) model of global sourcing with multiple inputs and multilateral bargaining.
} 
assume that both inputs are fully relationship-specific and have no value besides for the production of output $y$. The revenue from selling $y$ can be written as:

$$
R=p \cdot y=A^{1-\alpha}\left[\left(\frac{h}{\eta}\right)^{\eta}\left(\frac{m}{1-\eta}\right)^{1-\eta}\right]^{\alpha}
$$

In the following we characterize our setup for the repeated game which consists of an initialization phase and a stage game which is repeated ad infinitum.

\section{Initialization phase}

In the initialization phase key parameters of the game are determined. It has two steps:

1. $\mathrm{H}$ enters the market and learns its unit costs $c_{h}$, the headquarter intensity $\eta \in(0,1)$, the demand parameters $\alpha$ and $A$, and its time-discount factor $\delta_{H} \in(0,1)$. All these parameters are public information and remain the same for all periods of the repeated stage game.

2. We assume that there is a continuum of potential suppliers, which are all identical except for the marginal $\operatorname{costs} c_{m}$ that they would incur in the relationship with $H$. In particular, all potential suppliers face the same trade $\operatorname{cost} \tau$, have the same outside option $\omega_{M}$, and a common discount factor $\delta_{M} \in(0,1) .{ }^{3}$ The costs $c_{m}$ are distributed across potential suppliers according to some distribution $g\left(c_{m}\right)$ with corresponding cumulative density function $G\left(c_{m}\right)$. The headquarter $H$ gets initially matched with some supplier $M_{0}$ with unit $\operatorname{costs} c_{m}^{0}$ randomly drawn from $g\left(c_{m}\right)$. This initial matching is costless.

\section{Stage game}

After the initialization phase the stage game starts. It has the following consecutive steps:

1. Proposal stage (cheap talk): $\mathrm{H}$ can make $\mathrm{M}$ a non-binding and non-contractible proposal specifying investment levels $(h, m)$ and an ex-post bonus payment $B$ to $\mathrm{M}$. We call this proposal, which is essentially just cheap talk, a relational contract.

2. Participation decision stage: The supplier $M$ decides upon his participation in the relationship with $\mathrm{H}$ according to his outside option $\omega_{M}$.

3. Investment stage: The headquarter $\mathrm{H}$ and the supplier $\mathrm{M}$ simultaneously choose their non-contractible input investments $(h, m)$.

4. Information stage: $\mathrm{H}$ and $\mathrm{M}$ learn the investment level of their production partner.

5. Bargaining stage: If a relational contract was proposed, $\mathrm{H}$ can decide to pay the bonus $B$ to M. Otherwise the surplus is split according to an asymmetric Nash bargaining, where $\beta \in(0,1)$ is H's and $(1-\beta)$ is, respectively, M's bargaining power.

6. Profit realization stage: The final output is produced and sold. The surplus is divided as specified in stage 5 .

\footnotetext{
${ }^{3}$ Notice that $\delta_{M}$ need not coincide with the headquarter's $\delta_{H}$. See the discussion below. Moreover, in Section 4.2 we also consider the case where suppliers are heterogeneous in their discount factors $\delta_{M i}$.
} 
At first we ignore supplier search and potential re-matching and assume that $H$ contracts with the initial partner $M_{0}$ forever. Below we introduce the option to switch suppliers, which then extends the stage game by one further step.

Notice that our setting is a game of public monitoring. Thus, following Abreu (1988) we can identify a simple strategy profile that implements the production of the first-best (joint profit-maximizing) output level as a subgame-perfect Nash equilibrium (SPNE) of the repeated game. ${ }^{4}$ As such it will be sufficient to apply the one-step deviation principle to one arbitrary (but representative) stage game in order to confirm a strategy as an equilibrium. We make use of this property in the following implementation.

\section{Static Nash Equilibrium}

Before analyzing the repeated game, we briefly consider a static setting where the stage game is only played once. In such a case, we end up with identical hold-up and underinvestment problems as described by Antràs (2003) or Antràs and Helpman (2004).

By backward induction, first consider the bargaining stage 5. Since $\{(h, m), B\}$ is not legally enforceable, it is always optimal for the headquarter not to pay the bonus $B$. Hence, the two parties will engage in Nash bargaining. Anticipating this, at the investment stage 3 , the headquarter and the supplier choose $h$ and $m$, respectively, in order to maximize their individual payoffs

$$
\max _{h} \beta R(h, m)-c_{h} h, \quad \max _{m}(1-\beta) R(h, m)-\tau c_{m} m .
$$

The resulting investment levels are denoted by $\tilde{h}$, and $\tilde{m}$, and can be found from calculating mutual best responses. They are identical to the results from Antràs (2003):

$$
\tilde{h}=\frac{\alpha \beta \eta}{c_{h}} \tilde{R}, \quad \tilde{m}=\frac{\alpha(1-\beta)(1-\eta)}{\tau c_{m}} \tilde{R},
$$

where

$$
\tilde{R}=\mathcal{A}\left[\left(\frac{\beta}{c_{h}}\right)^{\eta}\left(\frac{1-\beta}{\tau c_{m}}\right)^{1-\eta}\right]^{\frac{\alpha}{1-\alpha}} \quad \text { with } \quad \mathcal{A} \equiv A \alpha^{\frac{\alpha}{1-\alpha}} .
$$

Thus, in this static world, the equilibrium payoffs are, respectively, given by

$$
\pi_{H}^{N}=\beta \tilde{R}-c_{h} \tilde{h}, \quad \pi_{M}^{N}=(1-\beta) \tilde{R}-\tau c_{m} \tilde{m}
$$

and the participation of the supplier in stage 2 can simply be ensured by a low enough outside option, namely $\omega_{M} \leq \pi_{M}^{N}$, which we henceforth assume to hold.

Before proceeding, it is worth stressing that the assumption of full relationship-specificity may be restrictive, as intermediate inputs in reality often have some value on an outside market. To capture this, let us assume that the supplier could also sell $m$ at price $p_{m}>\tau c_{m}$ elsewhere. This, in turn, improves his bargaining power vis-a-vis $H$. In particular, similar as in Baker et al. (2002), $H$ has to compensate $M$ for this alternative use of the input, and bargain over the surplus value of the relationship. In stage 3, the two agents then face the following problems which can be solved in a similar fashion as before:

\footnotetext{
${ }^{4}$ In the following, we use the terms joint profit-maximizing and first-best investment levels synonymously.
} 


$$
\begin{array}{ll}
\max _{h} & -p_{m} m+\beta R(h, m)-c_{h} h, \\
\max _{m} & p_{m} m+(1-\beta)\left(R(h, m)-p_{m} m\right)-\tau c_{m} m=(1-\beta) R(h, m)-\left(\tau c_{m}-\beta p_{m}\right) m,
\end{array}
$$

where we assume that $\tau c_{m}>\beta p_{m}$. It is easy to see that the resulting investments $\tilde{m}$ and $\tilde{h}$ and the payoff $\pi_{M}^{N}$ are increasing, while $\pi_{H}^{N}$ is decreasing in $p_{m} .{ }^{5}$ Intuitively, an improvement in the outside market conditions incentivizes the supplier to produce, as he is fully compensated for the opportunity costs. The headquarter, in turn, also contributes more to the relationship, but ends up with a lower Nash payoff due to the required transfer.

To stay consistent with the baseline model from the literature, we set $p_{m}=0$ in the remainder of this paper so that (4) and (5) are the solutions to the static stage game.

\section{Relational contracts without supplier re-matching}

We now turn to the repeated game and study how first-best input investments can be implemented by an informal agreement despite the absence of any legally binding contracts. In this section we still consider that the firm collaborates with a fixed partner, namely the initial supplier $M_{0}$. The strategy profile of our repeated game has two states, the cooperative and the non-cooperative one. The game starts in the cooperative state, where $\mathrm{H}$ promises a bonus payment $B$ to $M$, and stipulates first-best (joint profit-maximizing) input quantities $h^{*}$ and $m^{*}$. We denote joint first-best profits by

$$
\pi^{J F B}=R\left(h^{*}, m^{*}\right)-c_{h} h^{*}-\tau c_{m} m^{*},
$$

and the corresponding input quantities and revenue are given by

$$
h^{*}=\frac{\alpha \eta}{c_{h}} R^{*}>\tilde{h}, \quad m^{*}=\frac{\alpha(1-\eta)}{\tau c_{m}} R^{*}>\tilde{m}, \quad R^{*}=\mathcal{A}\left(c_{h}^{\eta}\left(\tau c_{m}\right)^{1-\eta}\right)^{\frac{-\alpha}{1-\alpha}}>\tilde{R} .
$$

In the cooperative state, $\mathrm{H}$ and $\mathrm{M}$ actually produce those input levels $h^{*}$ and $m^{*}$ in stage 3. In stage $5, \mathrm{H}$ pays $\mathrm{M}$ the agreed upon bonus $B$ (that we derive below) and keeps the residual revenue for herself. The per-period payoffs for the two parties under this relational contract $(\mathrm{RC})$ are thus given by

$$
\pi_{H}^{R C}=R^{*}-c_{h} h^{*}-B, \quad \pi_{M}^{R C}=B-\tau c_{m} m^{*} .
$$

When a deviation from this informal agreement $\left\{\left(h^{*}, m^{*}\right), B\right\}$ occurs, the game switches to the non-cooperative state from the next period onwards and stays in that state forever. In the non-cooperative state, $\mathrm{H}$ and $\mathrm{M}$ make input investments as in the static game, see (4), and earn payoffs $\pi_{i}^{N}$ in every period as given in (5). ${ }^{6}$ In the deviation period, the respective deviator chooses his or her payoff-maximizing input investment given first-best

\footnotetext{
${ }^{5}$ An increase of $p_{m}$ has, indeed, analogous effects as a reduction of the supplier's unit $\operatorname{costs} c_{m}$.

${ }^{6}$ Nash reversion is a commonly assumed punishment strategy, and in our context it has the advantage of bringing the model back to the baseline framework by Antràs (2003). In a supplementary online appendix we consider different penal codes as robustness checks, see the discussion below.
} 
investments of the other party, while anticipating that the surplus is divided via Nash bargaining since inputs can be observed before revenue is realized. We denote the deviation investments as $h^{D}$ and $m^{D}$, respectively, which can be computed as follows

$$
\max _{h^{D}} \beta R\left(h^{D}, m^{*}\right)-c_{h} h^{D}, \quad \max _{m^{D}}(1-\beta) R\left(h^{*}, m^{D}\right)-\tau c_{m} m^{D} .
$$

This leads to

$$
h^{D}=\frac{\alpha \eta \beta}{c_{h}} R\left(h^{D}, m^{*}\right), \quad m^{D}=\frac{\alpha(1-\eta)(1-\beta)}{\tau c_{m}} R\left(h^{*}, m^{D}\right),
$$

with $R\left(h^{D}, m^{*}\right)=\mathcal{A} \beta^{\frac{\alpha \eta}{1-\alpha \eta}}\left(c_{h}^{\eta}\left(\tau c_{m}\right)^{1-\eta}\right)^{\frac{-\alpha}{1-\alpha}}$ and $R\left(h^{*}, m^{D}\right)=\mathcal{A}(1-\beta)^{\frac{\alpha(1-\eta)}{1-\alpha+\alpha \eta}}\left(c_{h}^{\eta}\left(\tau c_{m}\right)^{1-\eta}\right)^{\frac{-\alpha}{1-\alpha}}$.

The deviation payoffs are thus given by

$$
\pi_{H}^{D}=\beta R\left(h^{D}, m^{*}\right)-c_{h} h^{D}, \quad \pi_{M}^{D}=(1-\beta) R\left(h^{*}, m^{D}\right)-\tau c_{m} m^{D} .
$$

In the following we show under which conditions the relational contract can be implemented as a SPNE of the repeated game, given the Nash reversion trigger strategy. First, after the proposal in stage 1 , the supplier decides in stage 2 on participation according to:

$$
B-\tau c_{m} m^{*} \geq \omega_{M}
$$

This participation constraint $(\mathrm{PC})$ requires that the bonus must at least compensate the supplier's full production costs (including trade costs) plus his outside option $\omega_{M}$.

Second, in stage 3 , adhering to the agreement and choosing first-best investment levels must be better for both parties than deviating once and reverting to the non-cooperative state in the future. We face the following incentive compatibility (IC) constraints,

$$
\begin{gathered}
\frac{1}{1-\delta_{H}} \pi_{H}^{R C} \geq \pi_{H}^{D}+\frac{\delta_{H}}{1-\delta_{H}} \pi_{H}^{N}, \\
\frac{1}{1-\delta_{M}} \pi_{M}^{R C} \geq \pi_{M}^{D}+\frac{\delta_{M}}{1-\delta_{M}} \pi_{M}^{N}
\end{gathered}
$$

where $\pi_{i}^{R C}, \pi_{i}^{D}$ and $\pi_{i}^{N}$ for $i=H, M$ are given by (5), (7), and (9). Rearranging (IC-H) and (IC-M) for $B$, we can identify the range of bonus payments for which relational contracting is incentive compatible:

$$
\begin{gathered}
B \leq R^{*}-c_{h} h^{*}-\left[\delta_{H} \pi_{H}^{N}+\left(1-\delta_{H}\right) \pi_{H}^{D}\right] \equiv B_{H}(\delta) \\
B \geq \tau c_{m} m^{*}+\left[\delta_{M} \pi_{M}^{N}+\left(1-\delta_{M}\right) \pi_{M}^{D}\right] \equiv B_{M}(\delta)
\end{gathered}
$$

where it follows from (IC-M') and (PC-M) that the supplier's participation constraint is always satisfied, since $\pi_{M}^{D}>\pi_{M}^{N}>\omega_{M}$ always holds.

In Figure 1 we illustrate this bonus $B_{i}$ for which the respective player is indifferent between sticking to, and deviating from the RC for the special case where the headquarter and the supplier have a common discount factor $\left(\delta_{H}=\delta_{M}=\delta\right)$. As can be seen, the firm is willing to transfer a higher maximum bonus $B_{H}(\delta)$ at higher $\delta$, since the $\mathrm{RC}$ is 
relatively more attractive when agents are more patient. By the same argument, the minimum required bonus $B_{M}(\delta)$ is lower at higher levels of $\delta$. Clearly, the RC can only be incentive compatible if $B_{H}(\delta) \geq B_{M}(\delta)$, i.e., if the maximum bonus that $H$ is willing to pay exceeds the minimum bonus required by $M$. Since $B_{H}(\delta)$ is linearly increasing and $B_{M}(\delta)$ linearly decreasing in $\delta$, the following is true: If we can find a $\underline{\delta}$ for which $B_{H}(\underline{\delta})=B_{M}(\underline{\delta})$ holds, then for all $\delta \geq \underline{\delta}$ the RC can be made incentive compatible with an appropriate bonus. This critical discount factor $\underline{\delta} \in(0,1)$ lies at the intersection of the two linear curves, and is characterized formally in Proposition 1. The grey area in Figure 1 depicts the set of feasible bonus payments for which the RC is an equilibrium of the repeated game. Notice that the firm has no incentive to transfer more than necessary to make the RC incentive compatible for M. Hence, she will offer a $B$ such that (IC-M') binds with equality, and we denote the resulting optimal bonus payment by $B^{*}(\delta)$ which is decreasing in $\delta$. Thus, when agents are more patient, it is cheaper for the firm to sustain the cooperation with supplier $M_{0}$ and allows her to keep a larger relational rent.

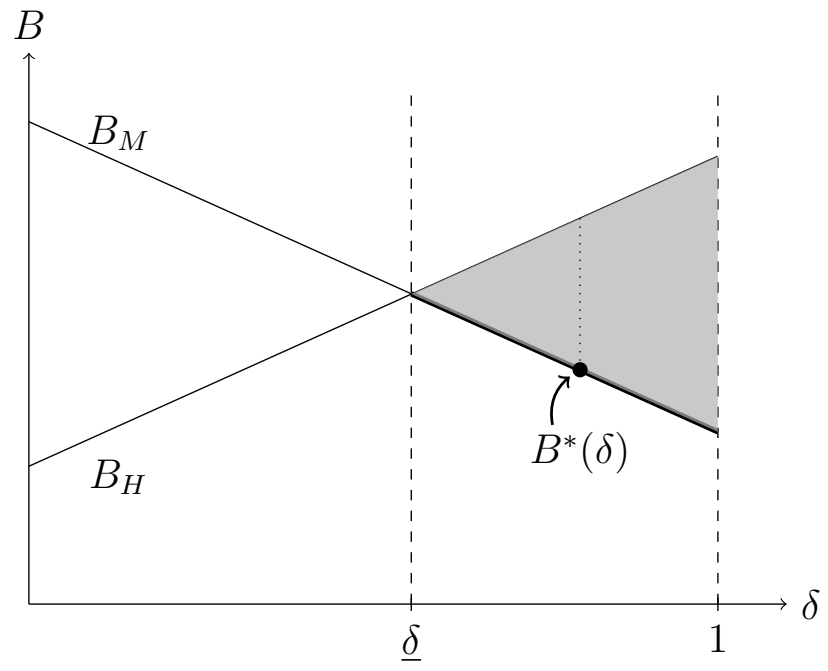

Figure 1: Incentive-compatible bonus payments

This logic carries over to the realistic case where discount factors are heterogeneous, i.e., where the foreign suppliers are less patient than the domestic headquarter corporation $\left(\delta_{H}>\delta_{M}\right)$. As shown in the following Proposition 1, the RC can still be implemented in equilibrium when agents are patient enough on average:

Proposition 1. Under the relational contract $(R C)$ first best investment levels $\left(h^{*}, m^{*}\right)$ can be supported as a SPNE of the repeated game if

$$
\widetilde{\delta}\left(\delta_{H}, \delta_{M}, \alpha, \beta, \eta\right) \equiv \frac{\sum_{i} \delta_{i}\left(\pi_{i}^{D}-\pi_{i}^{N}\right)}{\sum_{i}\left(\pi_{i}^{D}-\pi_{i}^{N}\right)} \geq \frac{\sum_{i} \pi_{i}^{D}-\pi^{J F B}}{\sum_{i}\left(\pi_{i}^{D}-\pi_{i}^{N}\right)} \equiv \underline{\delta}(\alpha, \beta, \eta),
$$

with bonus payment $B^{*}\left(\delta_{M}\right)=\tau c_{m} m^{*}+\left[\delta_{M} \pi_{M}^{N}+\left(1-\delta_{M}\right) \pi_{M}^{D}\right]$.

\section{Proof. See Appendix A}

Several points are worth noting about this result. First, the agents in our model encounter a situation that may be thought of as a repeated prisoner's dilemma. This 
follows from the fact that the ordering of payoffs $\pi_{i}^{D}>\pi_{i}^{R C}>\pi_{i}^{N}$ holds both for the headquarter $(i=H)$ and for the supplier $(i=M)$. If the $\mathrm{RC}$ arises, it makes the supplier strictly better off compared to static Nash play, even though the firm only pays him the minimum required bonus. More specifically, we have $\pi_{M}^{R C}=B^{*}-\tau c_{m} m^{*}=$ $\left[\delta_{M} \pi_{M}^{N}+\left(1-\delta_{M}\right) \pi_{M}^{D}\right]>\pi_{M}^{N}$. The intuition is the strategic value of the deviation option which is capitalized in the optimal bonus payment $B^{*}\left(\delta_{M}\right)$. We could also introduce an explicit notion of relational rent sharing, by assuming that $\mathrm{H}$ offers $\mathrm{M}$ a bonus payment $B_{M}\left(\delta_{M}\right)<B^{*}<B_{H}\left(\delta_{H}\right)$. But our model provides a rationale why informal RCs are to the mutual benefit of both parties even without this rent sharing.

Second, in spirit of the literature on repeated games with heterogeneous time preferences (see Harrington 1989; Haag and Lagunoff 2007), Proposition 1 shows that sustaining the $\mathrm{RC}$ in equilibrium requires a sufficiently high average patience level, but not necessarily that both agents are patient. More specifically, in our model, the weighted average of $\delta_{H}$ and $\delta_{M}$ (that we denote by $\widetilde{\delta}$ ) must exceed some critical level $\underline{\delta}$, where the weights are given by the relative deviation incentives $\left(\pi_{i}^{D}-\pi_{i}^{N}\right)$ of the firm and the supplier, respectively. If condition (10) holds, the (patient) firm can ensure the cooperation of the (impatient) supplier $M_{0}$ by an appropriate bonus payment $B^{*}\left(\delta_{M}\right)$, which is smaller the higher $\delta_{M}$ is. ${ }^{7}$ Also notice that (10) boils down to $\widetilde{\delta}=\delta \geq \underline{\delta}$ if both agents have the same discount factor, in which case the $\mathrm{RC}$ can be implemented if $\delta$ is high enough.

Third, it is evident from (10) that the demand parameter $A$, as well as the unit costs $c_{h}$ and $c_{m}$ and the trade costs $\tau$ do not affect the critical discount factor $\underline{\delta}$, which solely depends on the demand elasticity parameter $\alpha$, the headquarter intensity $\eta$, and the bargaining power $\beta$. Furthermore, the parameters $A, c_{h}, c_{m}$, and $\tau$ also cancel from the weighting terms $\left(\pi_{i}^{D}-\pi_{i}^{N}\right)$ on the LHS of (10), which depends only on $\delta_{H}, \delta_{M}, \alpha, \beta$ and $\eta$ (see Appendix A). This means that the unit cost level $c_{m}^{0}$ of the perpetual supplier $M_{0}$ is irrelevant for the question whether a RC with him is feasible or not. If $M_{0}$ happens to be more efficient and has lower $c_{m}^{0}$, or if he becomes more efficient and reduces $c_{m}^{0}$ over time (e.g., through learning effects), this would proportionally raise all payoffs $\pi_{i}^{D}, \pi_{i}^{R C}, \pi_{i}^{N}$ for $i=H, M$, and the bonus $B^{*}\left(\delta_{M}\right)$, but it would not affect the threshold $\underline{\delta}$. In Figure 1 , for example, the lines would still intersect at the same level of $\delta$. Intuitively, cost changes do not affect payoffs relatively stronger for one contractual arrangement than for another. ${ }^{8}$

Finally, it can be shown that the essence of Proposition 1 also remains unchanged with different penal codes than the Nash reversion trigger strategy that we take as our benchmark. In particular, in the supplementary appendix we first consider an optimal penal code along the lines of Abreu (1988) which involves "carrot-and-stick" punishment where, after a deviation, the other agent punishes the respective deviator with zero invest-

${ }^{7}$ Lehrer and Pauzner (1999) show that the set of feasible repeated game payoffs can be larger than the convex hull of the underlying stage game payoffs when both players $i$ are very patient in absolute terms, but still inhibit differing values of $\delta_{i}$. Intuitively, this works through temporary side payments from the very patient to the slightly less patient agent. In this paper, we sidestep those issues by restricting our attention to stationary bonus payments that remain constant over time, and by ignoring mixed strategy equilibria. Agents in our model can, thus, at most coordinate on $\pi^{J F B}$ via the RC but not on joint payoffs beyond.

${ }^{8}$ This property does not crucially hinge on the assumed functional forms in (1) and (2) with iso-elastic demand and Cobb-Douglas production, but this independence of $\underline{\delta}$ holds for any production and demand function such that the resulting payoffs $\pi_{i}^{D}, \pi_{i}^{R C}$, and $\pi_{i}^{N}$ are homogeneous of some common degree $b$ in these parameters. 
ments for $T$ periods, and then returns to the cooperative state. For this case we obtain a different critical discount factor that is decreasing in the punishment length $T$, but that is still independent of $c_{m}$ and $\tau$. Moreover, as a further robustness check, we have secondly developed an extension of our model where the firm cannot infer the quality of the input $m$ and is subject to fluctuations in the demand level $A$, similar as in the collusion model by Green and Porter (1984). Also in that case we can implicitly determine a critical discount factor that now depends on demand uncertainty, but still not on the production or the trade costs. The cost-orthogonality of the critical discount factor therefore seems to hold under fairly general conditions, and does not hinge on the peculiarities of the model parametrization or the punishment strategies.

\section{Supplier re-matching}

We now introduce the option for the headquarter to switch suppliers after every round of output realization. In our main analysis in Section 4.1., all potential suppliers differ only in their unit costs $c_{m}$ but are indentical otherwise. This captures the firm's search for an efficient partner who is able to provide the desired input with a given quality at low costs. In Section 4.2., we then relax the assumption that all suppliers have common time preferences and analyze the firm's search for a reliable partner who is more patient.

\subsection{Searching an efficient partner}

We add the following stage to the game, with all other stages remaining unchanged:

7. Re-matching stage: $\mathrm{H}$ can pay a publicly known fixed cost $F>0$ and re-match to a new supplier. Let $c_{m}^{t}$ be the unit cost of her current supplier, and $c_{m}^{t+1}$ the unit cost of the new supplier that she has encountered. This $\operatorname{cost} c_{m}^{t+1}$ is randomly drawn from the distribution function $g\left(c_{m}\right)$ and is perfectly observable to the headquarter.

For the ease of exposition, we make two simplifying assumptions in the main text. First, we consider a particular parametrization of $g\left(c_{m}\right)$ with only two possible realizations $\left\{c_{m}^{l}, c_{m}^{h}\right\}$, where $c_{m}^{h}>c_{m}^{l}>0$. Hence, there are only low-cost and high-cost suppliers. The share of low-cost suppliers in the universe of potential suppliers, and thus the probability to find such a partner in every round of re-matching is denoted by $P .{ }^{9}$ Second, we assume that the headquarter must re-match when she decides to engage in costly search, even when the supplier she encounters is less efficient than her current partner.

In the supplementary appendix, we relax both simplifications. In particular, there we consider i) a general distribution $g\left(c_{m}\right)$ from which $c_{m}$ is drawn, and ii) we separate the processes of supplier search and re-matching. Specifically, in that version of the model the firm pays a search cost $F$, encounters a candidate supplier, and re-matches only if that

\footnotetext{
${ }^{9}$ We thus assume a perfectly elastic supply of good component manufacturers. In the Chinese context considered below in the empirical part, this assumption appears quite plausible because the number of Chinese component manufacturers has been vastly increasing over time. Furthermore, in an interesting recent model of assortative buyer-supplier matching under complete contracts, Cajal-Grossi (2016) argues that search costs may also depend on the heterogeneity of potential suppliers. Our model is simpler in this respect, as it focuses on a single firm, and for simplicity assumes that search costs $F$ are fixed and independent of $g\left(c_{m}\right)$.
} 
candidate has strictly lower unit costs than her current supplier (otherwise she sticks to the old partner). It turns out that these more complicated versions yield insights which are similar to our simpler benchmark model.

We now analyze the re-matching decision and its interrelation with the contractual choice on RCs. Recall from the previous Section, where a change of suppliers was ruled out, that the critical discount factor $\underline{\delta}$ from (10) is independent of $c_{m}$. Since $\delta_{M}$ is identical for all (potential) $\mathrm{M}$, this together with the given $\delta_{H}$ fixes the weighted average patience level $\widetilde{\delta}$ which also does not depend on $c_{m}$. The headquarter therefore knows already at the beginning of the game if she will at any point be able to achieve a RC or not. We can therefore distinguish two cases in the subsequent analysis.

\subsubsection{The case with impatient agents $(\widetilde{\delta}<\underline{\delta})$}

With $\widetilde{\delta}<\underline{\delta}$, RCs can never be implemented regardless of the supplier's cost type. Agents would always deviate from the prescribed first-best behaviour, since they are too impatient on average, and thus Nash bargaining and the associated underinvestment emerge for sure.

Turning to the re-matching decision, at the end of every period the headquarter trades off the fixed cost $F$ against the expected payoff difference when changing partners. Recalling that there are only two supplier types, this re-matching decision has two dimensions:

1. if the current supplier is a high-cost type $\left(c_{m}^{t}=c_{m}^{h}\right)$, does the firm re-match?

2. if the current supplier is a low-cost type $\left(c_{m}^{t}=c_{m}^{l}\right)$, does she stick with that partner?

It is convenient to answer the second question first. Here it is important to notice that for the case of impatient agents the answer is unambiguously positive, that is, further re-matching makes no sense if the firm has found (or is initially matched with) a low-cost type. The reasons are twofold: i) a payoff improvement is only possible if the current supplier is a high-cost type, so that the firm has the chance $P$ to find a low-cost supplier, but not if the current supplier is already a low-cost type, and ii) since both partners only make Nash investments due to their average impatience, there exist no profitable deviations from this equilibrium strategy of mutual best responses for neither partner. It is thus never optimal for the firm to re-match further, even if $F$ is very low and/or $P$ is very high, but Nash play with the low-cost supplier will sustain over the entire game. Intuitively, re-matching is not a credible threat, and it cannot be exploited strategically in order to squeeze rents from the supplier. Both agents are aware that the same hold-up problem arises in every round, so it is better to avoid paying the fixed cost $F$.

Turning to the first question, suppose the initial supplier is a high-cost type $\left(c_{m}^{0}=c_{m}^{h}\right)$. We then need to analyze if the firms prefers to change suppliers at any point in time. Let $\pi_{H}^{N, l}$ and $\pi_{H}^{N, h}$ denote the headquarter's Nash payoff per period when matched with a low-cost, respectively, a high-cost supplier, with $\pi_{H}^{N, l}>\pi_{H}^{N, h}$ as directly evident from (5). The following condition must be satisfied in order for re-matching to occur:

$$
E\left[\pi_{H}^{R M, N} \mid c_{m}^{0}=c_{m}^{h}\right]>\frac{1}{1-\delta_{H}} \pi_{H}^{N, h},
$$

i.e., the expected payoff when changing partners must be higher than the continued Nash 
payoff with the initial high-cost supplier. Suppose it is profitable for the headquarter to re-match in period 0 . She thus pays $F$ and with probability $(1-P)$ gets matched to another high-cost supplier. If that happens, she earns $\pi_{H}^{N, h}$ from this relationship in period 1, and will then re-match again at the end of that round because re-matching must be profitable after round 1 when it was profitable after round 0 , and so forth. With probability $P$, however, she finds a low-cost supplier at the end of the round. If that happens, she stops changing partners and stays with this low-cost supplier in a long-term collaboration of repeated Nash-bargainings as shown before.

This decision problem can be written formally in the following way,

$$
\begin{aligned}
V_{0} & =\pi_{H}^{N, h}-F+\delta_{H} V_{1} \\
V_{i} & =(1-P)\left(\pi_{H}^{N, h}-F+\delta_{H} V_{i+1}\right)+P \frac{1}{1-\delta_{H}} \pi_{H}^{N, l}, \quad i=1,2, \ldots
\end{aligned}
$$

Observing that the decision problem is the same in every round $\left(V_{i}=V_{i+1}\right.$ for $\left.i=1,2, \ldots\right)$, the program can be simplified to

$$
V_{0}=\pi_{H}^{N, h}-F+\delta_{H} V_{1}, \quad V_{1}=\frac{1}{1-\delta_{H}(1-P)}\left((1-P)\left(\pi_{H}^{N, h}-F\right)+\frac{P}{1-\delta_{H}} \pi_{H}^{N, l}\right),
$$

and solving for $V_{0}$ we get the following expected profit when starting to change suppliers:

$$
E\left[\pi_{H}^{R M, N} \mid c_{m}^{0}=c_{m}^{h}\right]=\frac{1}{1-\delta_{H}(1-P)}\left[\pi_{H}^{N, h}-F+\frac{\delta_{H} P}{1-\delta_{H}} \pi_{H}^{N, l}\right]
$$

Combining expressions (11) and (12), we then obtain the following re-matching condition,

$$
F<\frac{\delta_{H} P}{1-\delta_{H}}\left[\pi_{H}^{N, l}-\pi_{H}^{N, h}\right] \equiv \bar{F}^{1},
$$

which states that the cost $F$ must be low enough in order for re-matching to occur. Notice that the critical search cost level $\bar{F}^{1}$ depends positively on $\delta_{H}$, i.e., re-matching is more attractive the more patient the headquarter is. The intuition is that future profits then matter more, and hence it becomes more important to find an efficient low-cost supplier. The patience level $\delta_{M}$, by contrast, does not directly affect the firm's search decision, although we have to keep in mind that $\widetilde{\delta}<\underline{\delta}$ is always assumed to hold. Moreover, $\bar{F}^{1}$ depends positively on $P$ and on the term $\left[\pi_{H}^{N, l}-\pi_{H}^{N, h}\right]$. This shows that re-matching is more likely the higher is the chance to find a low-cost supplier, and the larger is the headquarter's per-period payoff difference with a good and a bad partner.

Summing up, in the impatient agents case with $\widetilde{\delta}<\underline{\delta}$, we can conclude that no supplier turnover will ever arise if search costs are too high $\left(F \geq \bar{F}^{1}\right)$ or if the initial supplier is already a low-cost type. On the other hand, if the initial supplier is a high-cost type and if $F<\bar{F}^{1}$, the firm will change suppliers in every period until a low-cost supplier is found (which happens with strictly positive probability in finite time) and then stops re-matching forever. Notice that there is non-cooperative hold-up and underinvestment behaviour all the time, both with and without search and before and after the firm has found her ultimate match, because agents are too impatient on average to sustain cooperation. 


\subsubsection{Re-matching behaviour with patient agents $(\widetilde{\delta} \geq \underline{\delta})$}

Among patient agents RCs are feasible in principle, and would emerge for sure if supplier re-matching was ruled out. With respect to the re-matching decision, as before, it has two dimensions: i) start re-matching if $c_{m}^{t}=c_{m}^{h}$, and ii) stop re-matching if $c_{m}^{t}=c_{m}^{l}$.

Again we start with the second aspect. This analysis now becomes more involved, because a "cheat-and-run" behaviour might emerge as a profitable off-equilibrium strategy. In particular, suppose $c_{m}^{0}=c_{m}^{l}$, and the firm offers a RC to her initial low-cost supplier. However, rather than actually continuing the relationship with $M_{0}$, the firm may now deviate given the first-best supplier investment $m^{*}$ and earn $\pi_{H}^{D, l}$ in that period, re-match to a new supplier in order to avoid the punishment (Nash reversion) of the old partner, and then deviate-and-rematch in every subsequent round. Clearly, if $F$ is low and $P$ is high, this can be more attractive than the RC with the initial low-cost supplier, even in a setting where agents are patient. The reason is, essentially, that a profitable offequilibrium deviation strategy with payoff $\pi_{H}^{D}$ now exists, in contrast to the impatient agents case where everybody plays Nash. ${ }^{10}$ To rule out "cheat-and-run", we have to assume that the search costs are above a threshold, otherwise a RC would never form. In Appendix B we derive this lower bound $\widetilde{F}$ and show that it is increasing in $P$. The condition $F>\widetilde{F}$ then ensures that "cheat-and-run" will not emerge. As a consequence, given that $c_{m}^{t}=c_{m}^{l}$, a long-term RC relationship is established once a low-cost supplier is found and is sustained forever without further re-matching.

Turning to the first question, re-matching among patient agents may thus only occur if the initial supplier is a high-cost type, $c_{m}^{0}=c_{m}^{h}$, and as before it will actually occur if search costs $F$ are low enough. In particular, the expected payoff when starting to switch partners must be higher than the continuation payoff with the initial high-cost supplier,

$$
E\left[\pi_{H}^{R M, R C} \mid c_{m}^{0}=c_{m}^{h}\right]>\frac{1}{1-\delta_{H}} \pi_{H}^{R C, h} .
$$

If that condition is violated, the headquarter forms a $\mathrm{RC}$ with her initial high-cost supplier which is sustainable since $\widetilde{\delta}>\underline{\delta}$. If condition (14) is satisfied, however, the firm starts re-matching. Once she encounters a low-cost supplier, re-matching stops and she forms a long-term RC collaboration with that partner as shown before. But in every round where she switches partners, the firm encounters a high-cost supplier with probability $(1-P)$. It may thus take several periods before supplier turnover stops once and for all. Note that during this transition period with one-shot interactions both parties only make Nash investments, since they anticipate the supplier replacement in every round so that RCs are not credible. ${ }^{11}$ In other words, the RC only forms once the firm is satisfied with her match, stops searching and decides to launch a long-term collaboration (LTC).

Analogous to the case of impatient agents, the decision problem for patient agents can

\footnotetext{
${ }^{10}$ It is important to realize that "cheat-and-run" is an off-equilibrium strategy, because in this full information game M will realize the firm's deviation and deviate himself, thus leading to Nash investments in equilibrium.

${ }^{11}$ This is different when the firm is not forced to re-match when paying $F$ but has the option to keep the old supplier. In that model version, considered in the supplementary appendix, it can be optimal for very patient agents to offer a RC to a high-cost supplier in the transitory period, despite the ongoing search.
} 
be formalized by the following program:

$$
V_{0}=\pi_{H}^{N, h}-F+\delta_{H} V_{1}, \quad V_{1}=\frac{1}{1-\delta_{H}(1-P)}\left((1-P)\left(\pi_{H}^{N, h}-F\right)+\frac{P}{1-\delta_{H}} \pi_{H}^{R C, l}\right),
$$

which by solving for $V_{0}$ implies these expected profit when engaging in re-matching:

$$
E\left[\pi_{H}^{R M, R C} \mid c_{m}^{0}=c_{m}^{h}\right]=\frac{1}{1-\delta_{H}(1-P)}\left[\pi_{H}^{N, h}-F+\frac{\delta_{H} P}{1-\delta_{H}} \pi_{H}^{R C, l}\right]
$$

Plugging (15) into (14), we then obtain the critical search cost level $\bar{F}^{2}$ for this case,

$$
F<-\left(\pi_{H}^{R C, h}-\pi_{H}^{N, h}\right)+\frac{\delta_{H} P}{1-\delta_{H}}\left[\pi_{H}^{R C, l}-\pi_{H}^{R C, h}\right] \equiv \bar{F}^{2},
$$

which also depends positively on $\delta_{H}, P$, and on the payoff difference between a good and a bad partner that is now given by $\left[\pi_{H}^{R C, l}-\pi_{H}^{R C, h}\right]$. Moreover, $\bar{F}^{2}$ depends negatively on the term $\left[\pi_{H}^{R C, h}-\pi_{H}^{N, h}\right]$, that is, re-matching becomes less likely if launching a RC with the current high-cost supplier generates a larger payoff gain for the headquarter. Finally, for consistency, the upper bound $\bar{F}^{2}$ must be larger than the lower bound $\widetilde{F}$ derived before. As also shown in Appendix B, this ranking $\widetilde{F}<\bar{F}^{2}$ can be guaranteed by making appropriate restrictions on $g\left(c_{m}\right)$, namely that $c_{m}^{h}$ and $c_{m}^{l}$ are not too similar.

\subsubsection{The impact of cost dispersion}

The following Proposition summarizes the key theoretical findings derived so far:

Proposition 2. a) Suppose the headquarter is initially matched with a low-cost supplier $\left(c_{m}^{0}=c_{m}^{l}\right.$ ). When the agents are sufficiently patient on average (if $\widetilde{\delta} \geq \underline{\delta}$ ), the firm will collaborate with that supplier forever in a relational contract $(R C)$ agreement with $\left\{h^{*}, m^{*}\right\}$ and $B^{*}\left(\delta_{M}\right)$, assuming that re-matching costs are not too low $(F>\widetilde{F})$. When the agents are not patient enough on average (if $\widetilde{\delta}<\underline{\delta}$ ) the firm establishes a long-term collaboration of repeated Nash bargainings with that supplier.

b) With $c_{m}^{0}=c_{m}^{h}$ and $\widetilde{\delta}<\underline{\delta}$, the firm starts re-matching if $F<\bar{F}^{1}$ and continues until she finds a low-cost supplier. The $R C$ can never be implemented.

c) With $c_{m}^{0}=c_{m}^{h}$ and $\widetilde{\delta} \geq \underline{\delta}$, the firm starts re-matching if $F<\bar{F}^{2}$ and continues until she finds a low-cost supplier. The RC forms with the ultimate low-cost supplier, but not with any high-cost supplier.

For the single headquarter firm considered in our model, supplier turnover will thus either occur not at all, or otherwise take place in every stage game round until a lowcost supplier is found. Figure 2 illustrates these results. The left panel depicts the case where the current supplier is still a high-cost type, while the right panel focuses on the constellation with a low-cost supplier. The weighted average patience level $\widetilde{\delta}$ is fully determined by the given parameter values $\delta_{H}, \delta_{M}, \alpha, \beta$ and $\eta$, and is depicted on the vertical axis. The search costs level $F$ is on the horizontal axis in both panels. The critical discount factor $\underline{\delta}$ is shown as the horizontal line. Re-matching, and thus one-shot interactions, occur in the darkly shaded area if $F$ falls short of the respective critical level. 


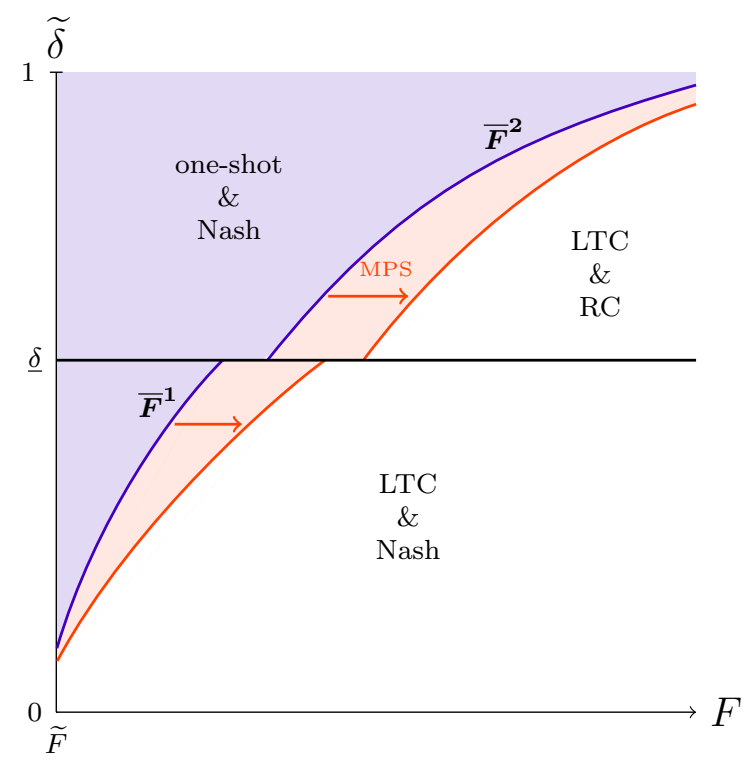

(a) $c_{m}^{0}=c_{m}^{h}$

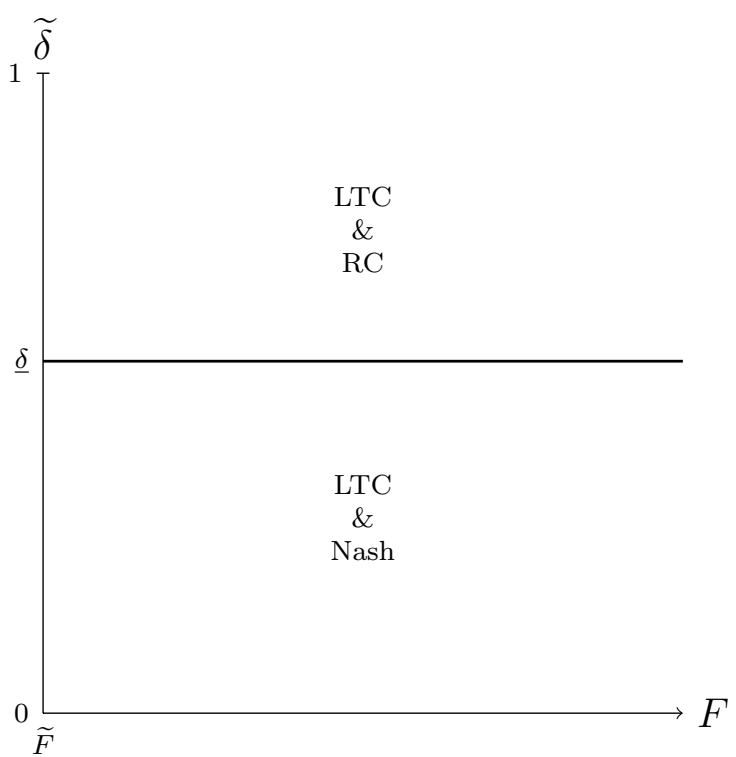

(b) $c_{m}^{0}=c_{m}^{l}$

Figure 2: Contractual and re-matching decision

In the right panel, we never observe any re-matching, since the firm already has a low-cost supplier. Below the solid line, agents are too impatient on average and thus engage in a long-term collaboration (LTC) with repeated Nash bargainings. Above the solid line, agents are patient enough on average and the $\mathrm{RC}$ forms immediately.

Turning to the left panel, we there depict the critical search cost levels $\bar{F}^{i}$ (with $i=1,2$ ) derived in (13) and (16), below which impatient (patient) agents start re-matching when their initial supplier is a high-cost type. Recall that both are increasing and convex in $\delta_{H}$, which for a given value of $\delta_{M}$ implies the concave relationship between $\widetilde{\delta}$ and $\bar{F}^{i}$ as shown in Figure 2. For the case of impatient agents (below the horizontal line) we generally observe Nash play. This is true, i) when search costs are high and the firm sticks with her initial high-cost supplier forever, and ii) also when search costs are low and the firm is in the process of finding a better partner. This can take multiple rounds, and after the firm has succeeded in finding a low-cost supplier, the constellation switches to the right panel of Figure 2. Now consider the patient agents case (above the horizontal line) in the left panel. When search costs are high, the firm sticks with her initial high-cost supplier forever and immediately establishes a RC. When search costs are low, however, the firm seeks for a better partner and re-matches until a low-cost type if found. During the transition, when the firm still deals with high-cost types, we observe Nash play despite the fact that agents are in principle sufficiently patient. The $\mathrm{RC}$ only forms once a lowcost supplier has been found, after which the constellation switches to the right panel. Put differently, the RC is established once the firm decides to stop re-matching, that is, the launching of a LTC with the current supplier causes the start of the RC. ${ }^{12}$

\footnotetext{
${ }^{12}$ In our baseline model, a LTC is thus a necessary but not a sufficient condition for a RC, as all RCs are also LTCs but not vice versa. When search and re-matching are separated (see supplementary appendix) a LTC is not even necessary, as RCs can then form on a short-term basis during the search for a better partner if agents are very patient. Yet, also in that case, there is a positive causal relationship, as the start of a LTC causes the $\mathrm{RC}$ for mildly patient agents, while impatient (very patient) agents never (always) have a RC in operation.
} 
In Proposition 3, we summarize how an increase in the suppliers' cost heterogeneity affects re-matching and contractual choices for the firm.

Proposition 3. A mean-preserving spread (MPS) in the distribution $g\left(c_{m}\right)$ (a larger difference between $c_{m}^{l}$ and $c_{m}^{h}$ at constant $P$ ) increases $\bar{F}^{1}$ and $\bar{F}^{2}$, and thus expands the parameter range where the headquarter engages in re-matching. For the patient agents case $(\widetilde{\delta}>\underline{\delta})$, this implies that the formation of RCs is postponed when the firm starts re-matching after the parameter change.

Proof. These results follow directly from (13) and (16), because the terms $\left(\pi_{H}^{R C, l}-\pi_{H}^{R C, h}\right)$ and $\left(\pi_{H}^{N, l}-\pi_{H}^{N, h}\right)$ are increasing when the MPS is performed, since $\pi_{H}^{R C}$ and $\pi_{H}^{N}$ are both monotonically decreasing in $c_{m}$.

In the left panel of Figure 2, we illustrate this Proposition by the shifts of $\bar{F}^{1}$ and $\bar{F}^{2}$ to the right. More precisely, when the firm's $(\widetilde{\delta}, F)$-combination falls inside the orange range in Figure 2, it has not searched before the parameter change, but after the MPS it will engage in re-matching so that supplier turnover is observed during a transitory period. The intuition is an increase in the relative benefit of collaborating with a low-cost supplier, which makes searching for such a type more attractive at unchanged values of the search costs $F$, average patience $\widetilde{\delta}$, and the other parameters. At the same time, notice that the higher cost dispersion neither affects the critical discount factor $\underline{\delta}$ nor the weighted average patience $\widetilde{\delta}$. Hence, the MPS does not directly affect whether the firm is able to establish a RC in the long-run. This contractual choice is only affected indirectly and temporarily, because more search and supplier turnover occurs. In the patient agents case, this induces the firm not to offer RCs immediately, but only when it has found the right match. Put differently, higher cost dispersion does not alter the firm's long-run decision whether to establish a $\mathrm{RC}$, but it may postpone the formation.

Finally, notice that an increase of the demand level $A$ or a decrease in trade costs $\tau$ also increase $\bar{F}^{1}$ and $\bar{F}^{2}$, because they also raise the relative benefit of collaborating with a low-cost supplier. Those parameter changes in $A$ or $\tau$ have therefore analogous effects to the MPS, i.e., they also lead to more search and fewer RCs during a transitory period.

\subsection{Searching for a reliable partner}

In the previous subsection, we have formalized the firm's search for a partner with low unit costs. Yet, as emphasized by Egan and Mody (1992), headquarter corporations in reality do not only care about the quality of the provided inputs and the efficiency of their suppliers, but also about their reliability when it comes to the agreed upon terms of delivery and other contractual details. We capture this notion of reliablility here in a particular way, by formalizing the firm's search for a partner with high $\delta_{M}$. The idea is that more patient suppliers are, ceteris paribus, more willing to sustain the cooperation with the firm, by reliably adhering to what has been stipulated in the relational agreement.

For this analysis, we assume that potential suppliers differ in their time preference rate but are identical in all other respects, in particular with respect to their unit costs $c_{m}$ which are now the same for all suppliers. The re-matching stage is adjusted as follows: 
7. Re-matching stage: $H$ can pay a publicly known fixed cost $F>0$ and re-match to a new supplier. Let $\delta_{M}^{t}$ be the discount factor of her current supplier, and $\delta_{M}^{t+1}$ the discount factor of the new supplier that she has encountered. This discount factor $\delta_{M}^{t+1}$ is randomly drawn from the distribution function $g\left(\delta_{M}\right)$ and is perfectly observable to the headquarter.

As before, we focus in the main text on a simple parameterization of $g\left(\delta_{M}\right)$ with only two realizations $\left\{\delta_{M}^{p a t}, \delta_{M}^{i m p}\right\}$, while deferring the general analysis to the supplementary appendix. The population of potential suppliers here consists of only two types, patient and impatient ones with $\delta_{M}^{p a t}$ and $\delta_{M}^{i m p}$, respectively, where $\delta_{M}^{p a t}>\delta_{M}^{i m p}$ and where $P_{\delta}$ is the share of patient suppliers in this population. Moreover, we restrict the parameter values of $\delta_{M}^{p a t}, \delta_{M}^{i m p}$ and $\delta_{H}$ such that $\widetilde{\delta}\left(\delta_{H}, \delta_{M}^{p a t}\right)>\underline{\delta}$ in $(10)$, while we allow $\widetilde{\delta}\left(\delta_{H}, \delta_{M}^{i m p}\right)$ to be above or below $\underline{\delta}$. That is, if supplier search was ruled out as in Section 3 , the RC would for sure be implemented with the patient type, but we consider both cases for the impatient type. ${ }^{13}$ Finally, we again assume that the firm must re-match after every round where she has decided to search for a new supplier.

First, realize that the firm has no incentive to engage in re-matching when the initial supplier $M_{0}$ is already a patient type, but she would start the $\mathrm{RC}$ with him immediately. The reason is that the firm cannot improve her payoff, since there is no better (more patient) supplier to be found, so it is always better avoiding the search cost $F$. Re-matching can only make sense if the initial supplier is an impatient type. When $\widetilde{\delta}\left(\delta_{H}, \delta_{M}^{i m p}\right)<\underline{\delta}$, the RC cannot be launched with $M_{0}$ and the agents would always play Nash, hence the firm has an incentive to search in order to establish a beneficial relational agreement with someone else. When $\widetilde{\delta}\left(\delta_{H}, \delta_{M}^{l}\right)>\underline{\delta}$, the firm could already start the RC with the initial (impatient) partner. Still there is an incentive to search, because both patient and impatient suppliers provide the same quality input $m^{*}\left(c_{m}\right)$ and generate the same revenue $R^{*}\left(c_{m}\right)$ in the RC, but the firm can reduce the required bonus from $B^{*}\left(\delta_{M}^{i m p}\right)$ to $B^{*}\left(\delta_{M}^{p a t}\right)$ when finding a patient supplier, thus raising her own payoff.

Formally, when the firm engages in re-matching, it is clear that agents play Nash in the respective period since the supplier anticipates his replacement. The RC only starts once a patient supplier is found, which happens with probability $P_{\delta}$ in every round of search. The firm, thus, solves the following problem:

$$
V_{0}=\pi_{H}^{N}-F+\delta_{H} V_{1}, \quad V_{1}=\frac{1}{1-\delta_{H}\left(1-P_{\delta}\right)}\left(\left(1-P_{\delta}\right)\left(\pi_{H}^{N}-F\right)+\frac{P_{\delta}}{1-\delta_{H}} \pi_{H}^{R C, p a t}\right),
$$

where $\pi_{H}^{R C, k}$ is the firm's payoff within the RC when collaborating with a supplier of patience level $k=\{i m p$, pat $\}$, where $\pi_{H}^{R C, p a t}>\pi_{H}^{R C, i m p}$. ${ }^{14}$ Solving for $V_{0}$ implies these expected profits when starting to re-match in search for a more reliable partner:

$$
E\left[\pi_{H}^{R M} \mid \delta_{M}^{0}=\delta_{M}^{i m p}\right]=\frac{1}{1-\delta_{H}\left(1-P_{\delta}\right)}\left[\pi_{H}^{N}-F+\frac{\delta_{H} P_{\delta}}{1-\delta_{H}} \pi_{H}^{R C, p a t}\right]
$$

\footnotetext{
${ }^{13}$ This rules out cases where the weighted average patience $\widetilde{\delta}$ is so low that the RC could never be implemented, regardless of the initial supplier's type. That case strikes us as being less interesting. Recall that unit costs and trade costs are irrelevant for those case distinctions.

${ }^{14}$ Note that $\pi_{H}^{N}$ would be the same for both supplier types, but is relevant here only for impatient ones.
} 
For the firm to start re-matching, this term in (17) must exceed the continuation payoff with the initial impatient supplier, which is $\pi_{H}^{N} /\left(1-\delta_{H}\right)$ in the first case with $\widetilde{\delta}\left(\delta_{H}, \delta_{M}^{i m p}\right)<\underline{\delta}$, and $\pi_{H}^{R C, i m p} /\left(1-\delta_{H}\right)$ in the second case with $\widetilde{\delta}\left(\delta_{H}, \delta_{M}^{i m p}\right)>\underline{\delta}$. This, in turn, allows us to derive critical search cost level below which the firm would actually start re-matching when her initial supplier is an impatient type. Those read as

$\bar{F}^{3}=\frac{P_{\delta} \delta_{H}}{1-\delta_{H}}\left(\pi_{H}^{R C, p a t}-\pi_{H}^{N}\right) \quad$ and $\quad \bar{F}^{4}=-\left(\pi_{H}^{R C, i m p}-\pi_{H}^{N}\right)+\frac{P_{\delta} \delta_{H}}{1-\delta_{H}}\left(\pi_{H}^{R C, p a t}-\pi_{H}^{R C, i m p}\right)$

in the first and in the second case, respectively. ${ }^{15}$

Summing up, when the firm searches for a reliable partner, the basic logic from the previous analysis - the search for an efficient supplier - carries over: The firm only rematches when the initial supplier is not already a "good" (i.e., patient or low-cost) type, and if supplier search is not too costly. Moreover, the RC does not start before the firm is ultimately satisfied with her match and decides to stop searching once and for all. In fact, also in this model version, the launching of a LTC causes the start of the RC, and in the second case considered above we find that search per se alters the contractual nature of buyer-supplier relationships. In particular, the firm would immediately start the RC with the initial impatient supplier if $F>\bar{F}^{4}$, but it will play Nash and replace him when search is not so costly (if $F<\bar{F}^{4}$ ) and only start the RC later. ${ }^{16}$

\section{Empirical application}

Our model implies a positive correlation between the prevalence of relational contracts (RC), and whether a buyer-supplier match is a long-term collaboration (LTC). This follows directly from Proposition 2 above: Not every LTC is a RC, but there is a positive connection since the decision to stop searching can cause the start of a relational agreement. In this final section, we empirically explore this key predictions of our theoretical framework. Moreover, we also test the prediction of Proposition 3 that more cost dispersion across the potential suppliers reduces both RCs and LTCs, essentially because the firm has a higher incentive to search for a better partner.

In Section 5.1. we first describe how we construct proxies for the two main variables, LTCs and RCs. In Section 5.2. we explore their correlation while controlling for many other firm- and product-level characteristics. Finally, in Section 5.3. we evaluate how they are affected by cost dispersion.

\subsection{Data and variables}

Exports of fresh Chinese suppliers. Our empirical evaluation exploits customs data from the Chinese General Administration of Customs for the period 2000 to 2006. For each

\footnotetext{
${ }^{15}$ As before, we introduce a lower bound for search costs $\tilde{F}$ in order to rule out "cheat-and-run"-behaviour. See the supplementary appendix.

${ }^{16}$ One subtle difference between search for an efficient and a reliable partner should be noted. For the latter we find that, whenever the firm decides to start re-matching, any future LTC will necessarily be a RC, while repeated Nash interactions can only occur if the firm never searches. This is different in Section 4.1, because impatient agents may start re-matching and eventually establish a LTC without ever being able to start a RC.
} 
year, the data allow us to identify exports of Chinese firms disaggregated by HS6-product and destination. For simplicity, we call these firm-product-destination combinations an export transaction. We drop all transactions with zero or negative values as well as export transactions with destination China. Moreover, to ensure consistency of the product categorization over time, we use the conversion table from UN Comtrade and convert the product code used for the years 2000 and 2001 into the HS 2002 codes.

In our theoretical framework, the headquarter deals with a new supplier when she decides to re-match. To reflect this, we only consider transactions of fresh Chinese exporters which establish their first exporting activity, so that foreign importing firms cannot infer any quality signals from their previous exporting experiences. Moreover, we restrict our sample to new transactions realized in the US, which is the main destination for Chinese exports besides Hong-Kong and Macao. This restriction allows us to abstract from the possible variation in the destination markets' contracting environments. Specifically, our sample is composed of Chinese firms $i$ which export a product $j$ to the US in year $t$, where $t=\{2001,2002,2003\}$, but which have not exported anything to any destination outside China during the previous years since 2000. ${ }^{17}$ We exclude all product categories $j$ with fewer than 10 active firms, and those where control variables are not available. The final sample then includes 16,150 fresh Chinese exporters, starting a total of 63,580 new export transactions, and spans 1,004 different HS6-digit product categories.

Match durations. Following the fresh Chinese exporters over time, we observe which firms that started an exporting activity in the US market in year $t$ still export the same product $j$ to the US after three years (in $t+3$ ), as opposed to those which have terminated that exporting activity in the meantime. Of the 63,580 transactions in our sample, it turns out that $27,572(43.3 \%)$ are terminated after less than one year, while 20,402 (32.1\%) of them endure for more than 3 years. ${ }^{18}$ Aggregating to the HS6 product level, we then compute the share of transactions in product $j$ that got started in $t=\{2001,2002,2003\}$ and that are still active in year $(t+3)$. This gives us our measure on the average match duration in product $j$, which we use as our main explanatory variable: the share of LTCs.

Relational contracts. Measuring the dependent variable - the share of RCs - is more challenging, because the various explicit and implicit match-specific contractual arrangements between the American buyer and the Chinese supplier are, almost by definition, not observable to the researcher. To still make some progress, we exploit the Chinese custom data which provides some further information about the type of arrangement between the partners. In particular, as our measure for the prevalence of RCs, we use the transactions realized using processing trade arrangements - a data feature that has been previously utilized in somewhat different, but related contexts. ${ }^{19}$

\footnotetext{
${ }^{17}$ As a robustness check, we also consider an alternative approach and only require that firms did not export anything to anywhere in year $(t-1)$. Results turn out to be very similar to those reported below.

${ }^{18}$ Ideally, we would like to observe if the Chinese exporter still deals with the same US importer, but the data do not allow us to do so. Nevertheless, our duration measure provides a very similar pattern to the one observed by Monarch (2015) who is able to use confidential US Customs data on US import transactions from China, where firms on both sides are uniquely identified. He finds that $45 \%$ of US importers change their Chinese partner from one year to the next. This number is quite close to the one obtained in our data (43.3\%).

${ }^{19}$ See Feenstra and Hanson (2005), Fernandes and Tang (2012), Kee and Tang (2016), Manova and Yu (2016).
} 
Why is processing trade a reasonable proxy for relational contracts? The rationale is the following: First, processing arrangements require to deal with a specific foreign client. An approval from provincial-level commerce departments must be sought by the Chinese firm before it can engage in processing trade and must include details on the foreign partner. The documents for application notably require the draft agreement about the deal signed by the Chinese supplier with its foreign partner, thus requiring a certain amount of familiarity between the two parties. Second, and more importantly, processing arrangements have some specific features directly related to our theoretical modelling of RCs. In particular, under fixed-fee agreements, Chinese companies export the finished goods and receive only a fixed processing fee. This fee is proportional to the number of processed products, which in turn limits the scope for bargaining and is close in spirit to the bonus payment featured in our model. Fixed-fee agreements are also associated with another interesting feature: the headquarter provides the intermediate inputs to its supplier. As a consequence, the supplier does not have to advance the money for buying these inputs. Using evidence from Rwanda's Coffee Mills, this feature has previously been identified by Marchiavello and Morjaria (2014) as a major indicator for relational contracts (in their paper, the coffee farmer receive inputs from the coffee mill). If the relational contract is destroyed, the supplier has to pay the entire costs of inputs upfront. These funds must be borrowed, and a credit constrained Chinese supplier might not be able to obtain the necessary liquidity. Moreover, another related feature of these processing trade arrangements is that it allow the US importer to send equipments and machineries to the Chinese suppliers duty-free. The machineries have to be used in the production line specifically dedicated to the production of goods for the respective foreign (US) partner, and thus, these transactions indicate a strong interlinked buyer-supplier relationship.

Summing up, in our empirical analysis we consider two specific proxies for the prevalence of RCs. The first and somewhat wider measure is the overall share of all transactions realized using processing trade arrangements in a product $j$. Then, as a second and narrower measure, we only consider processing arrangements with fixed-fee and/or with imported equipments supplied by the foreign party, and then build the share of these particular transactions among all transactions within the respective product. Both proxies are, arguably, only imperfect measures. Still, we believe that they capture the essence of RCs fairly well in at least some dimensions, so that our approach is a useful first step to gauge the empirical relevance of our theoretical results in the broad, but highly relevant context of US input sourcing from China.

\subsection{Relational contracts and long-term collaborations}

Descriptive overview. Table 1 reports the duration of the transactions under processing and ordinary trade arrangements and reveals quite striking differences. With processing trade, almost $59 \%$ of the transactions last three years or more, while only $17 \%$ do not go beyond the first year. By contrast, the majority of ordinary arrangements (47\%) actually seem to be one-shot deals, and only $28.4 \%$ of them last for more than three years.

Digging deeper into the different types, we find that $20 \%$ of all processing trade transactions are either a fixed-fee arrangement, in which case the foreign party also provides the 
intermediate inputs, or one with supplied equipment by the US partner; around $13 \%$ of them actually have both features. Table 2 then provides similar statistics for the durations of these two sub-types, with fixed fees (columns 1 and 2) and with supplied equipments (columns 3 and 4). As can be seen, only $14-18 \%$ of those transactions last for less than a year, while 55-60 \% seem to be resilient long-term collaborations. The share of LTCs is, thus, rather similar to the one among all processing trade transactions.

Table 1: Duration of processing and non-processing transactions

\begin{tabular}{lcccc}
\hline \hline Duration of & \multicolumn{2}{c}{ With Processing } & \multicolumn{2}{c}{ Without Processing } \\
transactions & \# transactions & Percentage & \# transactions & Percentage \\
\hline$<1$ year & 1,325 & 17.0 & 26,247 & 47.0 \\
$>1$ year & 1,047 & 13.5 & 8,451 & 15.1 \\
$>$ 2 years & 840 & 10.8 & 5,268 & 9.4 \\
$>$ 3 years & 4,561 & 58.7 & 15,841 & 28.4 \\
\hline Total & 7,773 & 100.0 & 55,807 & 100.0 \\
\hline \hline
\end{tabular}

Table 2: Duration of processing transactions with fixed-fees and supplied equipments

\begin{tabular}{lcccc}
\hline \hline & \multicolumn{2}{c}{ Processing } & \multicolumn{2}{c}{ Processing } \\
$\begin{array}{l}\text { Duration of } \\
\text { transactions }\end{array}$ & $\begin{array}{c}\text { \#ith fixed-fees } \\
\text { \# transactions }\end{array}$ & Percentage & \# transactions & Percentage \\
\hline$<$ 1 year & 445 & 18.3 & 160 & 14.1 \\
$>$ 1 year & 357 & 14.7 & 160 & 14.1 \\
$>$ 2 years & 279 & 11.5 & 132 & 11.6 \\
$>$ 3 years & 1,353 & 55.6 & 684 & 60.2 \\
\hline Total & 2,434 & 100.0 & 1,136 & 100.0 \\
\hline \hline
\end{tabular}

An important observation is that quite a few of the Chinese exporters in our data are owned by multinational corporations. It is important to take these ownership structures into account, as Chinese foreign affiliates may differ systematically in their economic behaviour from independent contractors. ${ }^{20}$ Tables 3 and 4 are analogous to Tables 1 and 2, but exclude all transactions from Chinese foreign affiliates which are dependent subsidiaries or part of a joint venture. Two interesting facts emerge: First, while the number of transactions using ordinary trade decreases by only $15.8 \%$ (from 55,807 to 47,013 transactions), the overall number of processing trade transactions drops dramatically by $70.3 \%$ (from 7,773 to 2,308 ), although this drop is less pronounced for the two sub-types. In other words, the use of processing trade seems to be particularly common within the boundaries of the firm, but it is at the same time not limited to intra-firm trade relationships. Second, the data suggest that foreign affiliates' transactions are a bit more

\footnotetext{
${ }^{20}$ This ownership dimension does not feature in our theoretical model, where we assume that the supplier maintains all property rights over his assets. Notice, however, that the key trade-off formalized by our model is - in principle - not limited to arm's length outsourcing relationships, but can also arise with a similar intuition in the context of intra-firm trade (also see Kukharskyy and Pflüger, 2011). To reflect this, we conduct our estimations on the overall sample of all Chinese exporters and in our robustness checks, on a reduced sample where all Chinese foreign affiliates are excluded.
} 
Table 3: Duration of processing and non-processing transactions excluding multinational affiliates

\begin{tabular}{lcccc}
\hline \hline Duration of & \multicolumn{2}{c}{ With Processing } & \multicolumn{2}{c}{ Without Processing } \\
transactions & \# transactions & Percentage & \# transactions & Percentage \\
\hline$<$ 1 year & 430 & 18.6 & 23,344 & 49.7 \\
$>$ 1 year & 334 & 14.5 & 7,262 & 15.4 \\
$>$ 2 years & 290 & 12.6 & 4,344 & 9.2 \\
$>$ 3 years & 1,254 & 54.3 & 12,063 & 25.7 \\
\hline Total & 2,308 & 100.0 & 47,013 & 100.0 \\
\hline \hline
\end{tabular}

Table 4: Duration of processing transactions with fixed-fees and supplied equipments excluding multinational affiliates

\begin{tabular}{|c|c|c|c|c|}
\hline \multirow{2}{*}{$\begin{array}{l}\text { Duration of } \\
\text { transactions }\end{array}$} & \multicolumn{2}{|c|}{$\begin{array}{c}\text { Processing } \\
\text { with fixed-fees }\end{array}$} & \multicolumn{2}{|c|}{$\begin{array}{c}\text { Processing } \\
\text { with supplied equipments }\end{array}$} \\
\hline & \# transactions & Percentage & \# transactions & Percentage \\
\hline$<1$ year & 274 & 16.9 & 143 & 13.6 \\
\hline$>1$ year & 235 & 14.5 & 145 & 13.8 \\
\hline$>2$ years & 203 & 12.5 & 126 & 12.0 \\
\hline$>3$ years & 906 & 56.0 & 638 & 60.6 \\
\hline Total & 1,618 & 100.0 & 1,052 & 100.0 \\
\hline
\end{tabular}

resilient. In fact, dropping the foreign affiliates decreases the fraction of long-term collaborations and increases the share of one-shot transactions by 2-4 percentage points, both for processing and ordinary trade. However, it has basically no impact on the duration of processing transactions with fixed fees and/or with supplied equipments.

More importantly, dropping the foreign affiliates does not alter the sharp differences in duration between ordinary and processing trade transactions. Even when we exclusively focus on independent Chinese exporters, we still find a clear pattern that the latter type of arrangements have substantially longer durations. This is particularly clearly visible in Table 4: For the type of processing trade with fixed-fee and/or supplied equipment we find that the share of long-term collaborations is substantially higher than on average.

Summing up, the Chinese customs data yields a positive correlation between match durations (LTCs) and our empirical proxy for RCs. This is especially true when a fixed-fee agreement and/or the supply of equipment by the US partner is involved, which we believe are particularly good indicators that the two partners engage in relational contracting.

Correlations at the transaction level. Next, we present conditional correlations on the link between RCs and LTCs at the individual transaction-level. We use all new transactions by the fresh Chinese exporter $i$ in product $j$, and construct a dummy variable which equals one if the transaction was carried out under a processing trade arrangement. This dummy we then regress on another dummy variable indicating if the transaction is still observed in $t+3$ (value 1 ) or if it has ended in the meantime (value 0 ), while 
controlling for the ownership status of the Chinese firm. ${ }^{21}$

The results are reported in Table 5. Column 1 indicates that, when an export transaction is a continuing long-term collaboration (LTC), it has a 8.9 percentage points higher probability of being a RC. In column 2, we introduce a set of firm and HS6 digit product fixed effects to the regression. The rationale is that the use of processing trade may potentially vary across products within a firm, as argued by Manova and Yu (2016). Yet, while the magnitude of the coefficient associated with LTCs decreases substantially in column 2 , we still find a strong and significant correlation between LTCs and RCs even after taking into account any potential firm- or product-specific effects. Finally, in columns 3 and 4, we use the narrower proxy for RCs and the same picture emerges: If the relationship is a LTC, it is more likely a RC. ${ }^{22}$

Table 5: Relational-contracts and long-term collaborations: Transaction-level

\begin{tabular}{lcccc}
\hline \hline Dependent variable: & \multicolumn{2}{c}{ Processing transactions } & \multicolumn{2}{c}{$\begin{array}{c}\text { Processing with Fixed-fees } \\
\text { and/or supplied equipments }\end{array}$} \\
\hline LTC dummy & $0.089^{* * *}$ & $0.030^{* * *}$ & $0.031^{* * *}$ & $0.008^{* *}$ \\
& $(0.006)$ & $(0.005)$ & $(0.003)$ & $(0.003)$ \\
Foreign ownership & $0.286^{* * *}$ & & $0.018^{* * *}$ & \\
& $(0.009)$ & & $(0.004)$ & \\
\hline Firm fixed-effects & No & Yes & No & Yes \\
HS6 product fixed-effects & No & Yes & No & Yes \\
\hline Observations & 63,580 & 63,580 & 63,580 & 63,580 \\
$R^{2}$ & 0.162 & 0.879 & 0.007 & 0.844 \\
\hline \hline
\end{tabular}

Notes: Dependent variable: In column 1-2, the dummy variable takes the value one in the case part or all the transaction is realized under processing agreement, and zero otherwise. In column 3-4, the binary variable takes a value one for processing agreements with fixed-fees and/or supplied equipments, and zero otherwise. Each transaction is weighted such that each HS6 digit product is given the same weight. Columns 2 and 4
brackets using clustered standard errors at the HS6 level.

Correlations at the product level. In Table 6, we provide analogous estimations after aggregating the data to the HS6 product level. In columns 1-2, we regress the share of processing trade arrangements in product $j$ on the share of long-term transactions (lasting 3 years or more), and in columns 3-4 we use the respective share of processing transactions with fixed-fee and/or supplied equipment. In all regressions, we add the share of export transactions realized by a foreign affiliate as an additional control variable. Moreover, in column 2 and 4, we introduce a set of further product-level control variables, namely the capital-labor ratio, the human capital intensity, and the $R \& D$-sales ratio, which are

\footnotetext{
${ }^{21}$ Robust standard-errors are clustered at the HS6-digit level. In order to obtain transaction-level estimates that are directly comparable to the product-level estimations, we weight each transaction such that all products $j$ receive the same overall weight in the regression.

${ }^{22}$ Observe that the coefficient associated with foreign ownership is much smaller. In fact, foreign ownership seems to be a good predicator for the use of processing arrangements, but mainly when the processing transactions do not make use of fixed-fees and supplied equipment.
} 
Table 6: Relational-contracts and long-term collaborations: Product-level

\begin{tabular}{|c|c|c|c|c|}
\hline Dependent variable: & \multicolumn{2}{|c|}{$\begin{array}{c}\text { Share of processing } \\
\text { transactions }\end{array}$} & \multicolumn{2}{|c|}{$\begin{array}{l}\text { Share with fixed-fees } \\
\text { and/or supplied equipments }\end{array}$} \\
\hline LTC Share & $\begin{array}{c}0.088^{* * *} \\
(0.024)\end{array}$ & $\begin{array}{c}0.083^{* * *} \\
(0.024)\end{array}$ & $\begin{array}{c}0.050^{* * *} \\
(0.015)\end{array}$ & $\begin{array}{c}0.051^{* * *} \\
(0.014)\end{array}$ \\
\hline Foreign ownership & $\begin{array}{c}0.517^{* * *} \\
(0.033)\end{array}$ & $\begin{array}{c}0.492^{* * *} \\
(0.030)\end{array}$ & $\begin{array}{c}0.089^{* * *} \\
(0.017)\end{array}$ & $\begin{array}{c}0.085^{* * *} \\
(0.017)\end{array}$ \\
\hline ln Capital/Worker & & $\begin{array}{c}-0.020^{* * *} \\
(0.006)\end{array}$ & & $\begin{array}{c}-0.009^{* * *} \\
(0.004)\end{array}$ \\
\hline ln Skilled/Worker & & $\begin{array}{c}-0.081^{* * *} \\
(0.018)\end{array}$ & & $\begin{array}{c}-0.044^{* * *} \\
(0.011)\end{array}$ \\
\hline ln R\&D Sales & & $\begin{array}{l}-0.003 \\
(0.003)\end{array}$ & & $\begin{array}{c}-0.011^{* * *} \\
(0.002)\end{array}$ \\
\hline Nunn measure & & $\begin{array}{c}0.212^{* * *} \\
(0.038)\end{array}$ & & $\begin{array}{c}0.132^{* * *} \\
(0.019)\end{array}$ \\
\hline ln demand elasticity & & $\begin{array}{c}0.014^{* *} \\
(0.006)\end{array}$ & & $\begin{array}{c}0.009^{* *} \\
(0.004)\end{array}$ \\
\hline Observations & 1,004 & 1,004 & 1,004 & 1,004 \\
\hline$R^{2}$ & 0.304 & 0.363 & 0.047 & 0.131 \\
\hline
\end{tabular}

Notes: Dependent variable: In column 1-2, the dependent variable is the share of exports transactions using processing agreement on the overall number of transactions within a HS6 product. In column 3-4, the dependent variable is the share of exports transactions using processing agreement with fixed-fees and/or supplied equipments. Robust standard-errors in brackets.

standard measures for the headquarter-intensity $\eta \cdot{ }^{23}$ Moreover, we include the HS6-digit version of the relationship-specificity index by Nunn (2007), and add demand elasticities from Broda and Weinstein (2006) to capture $\alpha .^{24}$

Table 6 shows that there is a robust positive correlation between the share of LTCs and RCs also at the product level. The coefficients range between 5 and 9 percentage points, which is consistent with our previous results from Table 5. Adding the product-level control variables in columns 2 and 4 leaves the main coefficient basically unchanged.

Robustness checks. In Table 7 we perform a battery of robustness checks of our product-level regressions. First, in Columns 1 and 6, we exclude all the export transactions of foreign affiliates before aggregating the data. This leads to a decreasing number of observations as we still exclude products with less than 10 firms. The main coefficient for LTCs on RCs is almost identical to the one obtained in Table 6, however, and remains significant at the $1 \%$ level. Overall, this indicates that our results remain robust also in a smaller sample only consisting of independent Chinese-owned manufacturers.

\footnotetext{
${ }^{23}$ Those variables have been constructed by Nunn and Trefler (2013) using information for the US, hence, we implicitly assume that they are correlated with the factor-intensity of production in China. The information to construct the capital-labor ratio and the human capital intensity are from the U.S. Census Bureau's 2005 Annual Survey of Manufactures, while the data used to calculate the R\&D ratio are from the Orbis database, constructed by Bureau van Dijk Electronic Publishing. In both cases, the data are available at the 6-digit NAICS industry level and reclassified into the HS6-digit product classification. Similarly, skill intensity is the ratio of non-production worker wages to total worker wages. R\&D intensity is the R\&D expenditures divided by firm sales in each product.

${ }^{24}$ As data are disaggregated at the HS 10 digit level, we use the median value for each HS6 product.
} 
Table 7: Relational-contracts and long-term collaborations - robustness checks

\begin{tabular}{|c|c|c|c|c|c|c|c|c|c|c|}
\hline & $\begin{array}{c}\text { Drop } \\
\text { foreign }\end{array}$ & $\begin{array}{l}\text { Main } \\
\text { sector }\end{array}$ & $\begin{array}{l}\text { Drop zero } \\
\text { processing }\end{array}$ & $\begin{array}{c}\text { HS2 } \\
\text { fixed-effects }\end{array}$ & $\begin{array}{c}\text { HS2 } \\
\text { clusters }\end{array}$ & $\begin{array}{c}\text { Drop } \\
\text { foreign }\end{array}$ & $\begin{array}{l}\text { Main } \\
\text { sector }\end{array}$ & $\begin{array}{l}\text { Drop zero } \\
\text { processing }\end{array}$ & $\begin{array}{c}\text { HS2 } \\
\text { fixed-effects }\end{array}$ & $\begin{array}{c}\text { HS2 } \\
\text { clusters }\end{array}$ \\
\hline Dependent variable: & \multicolumn{5}{|c|}{$\begin{array}{l}\text { Share of processing } \\
\text { transactions }\end{array}$} & \multicolumn{5}{|c|}{$\begin{array}{l}\text { Share with fixed-fees } \\
\text { and/or supplied equipments }\end{array}$} \\
\hline LTC Share & $\begin{array}{c}0.083^{* * *} \\
(0.022)\end{array}$ & $\begin{array}{c}0.089^{* * *} \\
(0.030)\end{array}$ & $\begin{array}{c}0.088^{* * *} \\
(0.029)\end{array}$ & $\begin{array}{c}0.104^{* * *} \\
(0.026)\end{array}$ & $\begin{array}{c}0.083^{* *} \\
(0.033)\end{array}$ & $\begin{array}{c}0.054^{* * *} \\
(0.017)\end{array}$ & $\begin{array}{c}0.053^{* * *} \\
(0.016)\end{array}$ & $\begin{array}{c}0.065^{* *} \\
(0.028)\end{array}$ & $\begin{array}{c}0.054^{* * *} \\
(0.015)\end{array}$ & $\begin{array}{c}0.051^{* *} \\
(0.023)\end{array}$ \\
\hline Foreign ownership & & $\begin{array}{c}0.511^{* * * *} \\
(0.032)\end{array}$ & $\begin{array}{c}0.471^{* * *} \\
(0.037)\end{array}$ & $\begin{array}{c}0.426^{* * *} * \\
(0.034)\end{array}$ & $\begin{array}{c}0.492^{* * *} * \\
(0.054)\end{array}$ & & $\begin{array}{c}0.068^{* * *} * \\
(0.019)\end{array}$ & $\begin{array}{c}0.068^{* *} \\
(0.033)\end{array}$ & $\begin{array}{c}0.051^{* *} \\
(0.020)\end{array}$ & $\begin{array}{c}0.085^{* * *} * \\
(0.020)\end{array}$ \\
\hline ln Capital/Worker & $\begin{array}{c}-0.020 * * * \\
(0.005)\end{array}$ & $\begin{array}{c}-0.027^{* * *} \\
(0.008)\end{array}$ & $\begin{array}{c}-0.014^{*} \\
(0.008)\end{array}$ & $\begin{array}{c}0.026^{* *} \\
(0.012)\end{array}$ & $\begin{array}{c}-0.020^{*} \\
(0.012)\end{array}$ & $\begin{array}{c}-0.017^{* * *} \\
(0.005)\end{array}$ & $\begin{array}{c}-0.015^{* * *} \\
(0.005)\end{array}$ & $\begin{array}{l}-0.001 \\
(0.008)\end{array}$ & $\begin{array}{c}0.018^{* *} \\
(0.008)\end{array}$ & $\begin{array}{c}-0.009 \\
(0.007)\end{array}$ \\
\hline ln Skilled/Worker & $\begin{array}{c}-0.069^{* * *} * \\
(0.019)\end{array}$ & $\begin{array}{c}-0.121^{* * *} * \\
(0.025)\end{array}$ & $\begin{array}{c}-0.081^{* * *} \\
(0.021)\end{array}$ & $\begin{array}{c}-0.095^{* * *} \\
(0.026)\end{array}$ & $\begin{array}{c}-0.081 * * \\
(0.034)\end{array}$ & $\begin{array}{c}-0.062 * * * \\
(0.016)\end{array}$ & $\begin{array}{c}-0.053^{* * *} \\
(0.012)\end{array}$ & $\begin{array}{c}-0.054^{* * *} \\
(0.017)\end{array}$ & $\begin{array}{c}-0.043^{* * *} \\
(0.016)\end{array}$ & $\begin{array}{c}-0.044^{* *} \\
(0.018)\end{array}$ \\
\hline ln R\&D Sales & $\begin{array}{l}-0.004 \\
(0.004)\end{array}$ & $\begin{array}{l}-0.001 \\
(0.005)\end{array}$ & $\begin{array}{l}-0.000 \\
(0.004)\end{array}$ & $\begin{array}{r}-0.008^{*} \\
(0.005)\end{array}$ & $\begin{array}{l}-0.003 \\
(0.006)\end{array}$ & $\begin{array}{l}-0.004 \\
(0.003)\end{array}$ & $\begin{array}{l}-0.011^{* * *} \\
(0.003)\end{array}$ & $\begin{array}{c}-0.010^{* * *} \\
(0.003)\end{array}$ & $\begin{array}{l}-0.004 \\
(0.003)\end{array}$ & $\begin{array}{l}-0.011^{*} \\
(0.006)\end{array}$ \\
\hline Nunn measure & $\begin{array}{c}0.135 * * * \\
(0.033)\end{array}$ & $\begin{array}{c}0.225 * * * \\
(0.052)\end{array}$ & $\begin{array}{c}0.233^{* * *} \\
(0.049)\end{array}$ & $\begin{array}{l}0.110^{* *} \\
(0.048)\end{array}$ & $\begin{array}{c}0.212^{* * *} * \\
(0.058)\end{array}$ & $\begin{array}{c}0.123^{* * *} * \\
(0.025)\end{array}$ & $\begin{array}{c}0.118^{* * *} * \\
(0.023)\end{array}$ & $\begin{array}{c}0.157^{* * * *} \\
(0.039)\end{array}$ & $\begin{array}{c}0.073^{* * *} * \\
(0.027)\end{array}$ & $\begin{array}{c}0.132^{* * *} * \\
(0.046)\end{array}$ \\
\hline ln demand elasticity & $\begin{array}{c}0.017^{* * *} \\
(0.006)\end{array}$ & $\begin{array}{l}0.015^{*} \\
(0.009)\end{array}$ & $\begin{array}{c}0.024^{* * *} \\
(0.009)\end{array}$ & $\begin{array}{l}0.009^{*} \\
(0.005)\end{array}$ & $\begin{array}{l}0.014^{* *} \\
(0.007)\end{array}$ & $\begin{array}{c}0.011^{* *} \\
(0.005) \\
\end{array}$ & $\begin{array}{c}0.009^{* *} \\
(0.005)\end{array}$ & $\begin{array}{c}0.018 * * * \\
(0.007)\end{array}$ & $\begin{array}{c}0.001 \\
(0.004) \\
\end{array}$ & $\begin{array}{c}0.009^{* *} \\
(0.004)\end{array}$ \\
\hline$\overline{\text { Observations }}$ & 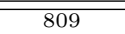 & 765 & $\overline{773}$ & $\overline{1,004}$ & 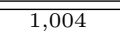 & $\overline{8009}$ & $\overline{765}$ & 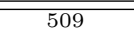 & $\overline{1,004}$ & $\overline{1,004}$ \\
\hline$R^{2}$ & 0.092 & 0.386 & 0.326 & 0.529 & 0.363 & 0.094 & 0.118 & 0.095 & 0.364 & 0.131 \\
\hline
\end{tabular}

Our second robustness check excludes all transactions which are not part of the firm's main sector of activity. Since many firms export multiple products, we define this main sector as the 2-digit HS product for which we observe the largest number of exported HS6 products. In columns 2 and 7, we only keep the transactions that belong to this main 2-digit sector of each firm, and again we obtain coefficients close to our baseline estimates.

The third robustness check consists of dropping all the HS6 products with zero processing transactions. In fact, our theoretical model predicts that some industries populated by impatient agent (with $\delta<\underline{\delta}$ ), never experience any relational contracting. And indeed, about 23 percent of all HS6 products do not have any processing trade transactions. Columns 3 and 8 show that the main coefficient for the LTC share increases when those cases are excluded, but the qualitative results remain the same.

Forth, we introduce a set of HS2-digit fixed effects to exploit the intra-sectoral variation with each 2 digit sector. The inclusion of these sectoral fixed effects generate results of the same magnitude to the one obtained in our baseline estimation, and the coefficient of interest remains significant at the $1 \%$ level (see columns 4 and 9).

Finally, we evaluate the impact of clustering the standard errors at different level of aggregation. In particular, we now cluster the standard errors at the more aggregate HS2-digit level. The coefficients in column 5 and 10 are, thus, identical as in columns 2 and 4 of Table 6 but the standard errors are larger. Still, the coefficient in column 5 and 10 of Table 7 remains significant at the $5 \%$ level. ${ }^{25}$

Summing up, all results from Tables 1-7 empirically support our main theoretical prediction from Proposition 2: There is a positive correlation between RCs and LTCs in the Chinese data, and this conclusion is very similar both for the wider and for the narrower proxy of relational contracting.

\footnotetext{
${ }^{25}$ We have also experiment clustering the standard errors at yet another level of aggregation using the corresponding 6-digit NAICS code associated with each HS-6 digit. In fact, the information used by Nunn and Trefler (2013) to construct the factor intensity of production are collected at the 6-digit NAICS level. Using a correspondence table, the authors link the NAICS 6-digit classification with HS6-digit product classification. This level of clustering also leaves the coefficient associated with the LTC Share significant at least at the $5 \%$ level. To save in space, we did not report these results.
} 


\subsection{The impact of cost dispersion}

In this last section, we evaluate the impact of cost dispersion on LTCs and RCs, and thereby empirically explore Proposition 3 which predicts a negative effect in both cases.

To construct an empirical proxy for the cost dispersion across all Chinese exporters of a product $j$, we approximate the transaction-specific marginal cost of the respective supplier by the unit-value of each transaction. The cost dispersion measure within product $j$ is then given by the standard deviation of the $\log$ of unit-values within the respective HS6 category during our period of observation. As usual, marginal costs are difficult to observe directly. Our underlying assumption, thus, follows standard practise and postulates that Chinese suppliers engage in fixed-markup pricing, so that the variation in unit-values captures cost dispersion. The recent findings by Monarch (2015) support this approach. Using confidential customs data, he shows that US importers paying the highest prices to their Chinese suppliers (also proxied by the unit-value in his paper) are most likely to change their partner in the future. This is consistent with the results of our model, where re-matching is more likely the higher are the marginal costs of the current supplier. ${ }^{26}$

Table 8: The impact of cost dispersion

\begin{tabular}{lcccc}
\hline \hline Dependent variable: & \multicolumn{2}{c}{ Share with fixed-fees } & \multicolumn{2}{c}{ Share of } \\
& and/or supplied equipments & long-term transactions \\
\hline Unit value SD & $-0.020^{* * *}$ & $-0.024^{* * *}$ & $-0.045^{* * *}$ & $-0.060^{* * *}$ \\
& $(0.004)$ & $(0.005)$ & $(0.010)$ & $(0.011)$ \\
Foreign ownership & $0.113^{* * *}$ & $0.109^{* * *}$ & $0.234^{* * *}$ & $0.231^{* * *}$ \\
& $(0.017)$ & $(0.016)$ & $(0.034)$ & $(0.034)$ \\
ln Capital/Worker & & $-0.008^{* *}$ & & 0.003 \\
& & $(0.004)$ & & $(0.010)$ \\
ln Skilled/Worker & & $-0.059^{* * *}$ & & -0.032 \\
& & $(0.011)$ & & $(0.022)$ \\
ln R\&D Sales & & $-0.010^{* * *}$ & & $0.008^{*}$ \\
& & $(0.002)$ & & $(0.004)$ \\
Nunn measure & & $0.137^{* * *}$ & & 0.044 \\
& & $(0.020)$ & & $(0.058)$ \\
ln demand elasticity & & 0.006 & & -0.006 \\
& & $(0.004)$ & & $(0.008)$ \\
\hline \hline Observations & 1,004 & 1,004 & 1,004 & 1,004 \\
$R^{2}$ & 0.054 & 0.142 & 0.058 & 0.070 \\
\hline \hline
\end{tabular}

Notes: Dependent variable: In column 1-2, the dependent variable is the share of exports transactions using processing agreement with fixed-fees and/or supplied equipments on the overall number of transactions within a HS6 product. In column 3-4, the dependent variable is the share of long term transactions. Robust standard-errors in brackets.

\footnotetext{
${ }^{26}$ Manova and Zhang (2012) argue that differences in unit-values could also reflects quality variations. In this case, our empirical proxy would be capturing heterogeneity in suppliers' quality. However, under iso-elastic demand and monopolistic competition, a marginal cost or a quality differences are isomorphic in the sense that they both enter equilibrium firm revenue in exactly the same way (see Melitz and Redding, 2014). As a result, while a lower quality would have the opposite effect on re-matching compared to lower cost, decreasing the variance of either quality or cost would have the same impact on the increase of LTCs. Hence, the interpretation of our results would be robust to the way we interpret differences in unit-values.
} 
The results in Table 8 show that cost dispersion is, indeed, negatively correlated with the share of $\mathrm{RCs}^{27}$ (column 1 and 2) as well as with the share of LTCs (column 3 and 4). This is the case for the baseline specifications in columns 1 and 3, and also when the other product-level control variables are included (columns 2 and 4). Quantitatively, the results suggest that, an increase of the standard deviation of the $\log$ of unit values by 1 percent is associated with a sizable decrease of $\mathrm{RC}$ arrangements by around 2 percentage points, and LTCs even decrease by more than 4 percentage points.

Table 9: The impact of cost dispersion - robustness checks (I)

\begin{tabular}{|c|c|c|c|c|c|c|c|c|c|c|}
\hline & $\begin{array}{c}\text { Drop } \\
\text { foreign }\end{array}$ & $\begin{array}{c}\text { Main } \\
\text { sector }\end{array}$ & $\begin{array}{l}\text { Drop zero } \\
\text { processing }\end{array}$ & $\begin{array}{c}\text { HS2 } \\
\text { fixed-effects }\end{array}$ & $\begin{array}{c}\text { HS2 } \\
\text { clusters }\end{array}$ & $\begin{array}{c}\text { Drop } \\
\text { foreign }\end{array}$ & $\begin{array}{c}\text { Main } \\
\text { sector }\end{array}$ & $\begin{array}{l}\text { Drop zero } \\
\text { processing }\end{array}$ & $\begin{array}{c}\text { HS2 } \\
\text { fixed-effects }\end{array}$ & $\begin{array}{c}\text { HS2 } \\
\text { clusters }\end{array}$ \\
\hline Dependent variable: & \multicolumn{5}{|c|}{$\begin{array}{c}\text { Share with fixed-fees } \\
\text { and/or supplied equipments }\end{array}$} & \multicolumn{5}{|c|}{$\begin{array}{c}\text { Share of long-term } \\
\text { collaborations }\end{array}$} \\
\hline Unit value SD & $\begin{array}{c}-0.018^{* * *} \\
(0.006)\end{array}$ & $\begin{array}{c}-0.024^{* * *} \\
(0.006)\end{array}$ & $\begin{array}{c}-0.030^{* * *} \\
(0.007)\end{array}$ & $\begin{array}{c}-0.014^{* * *} \\
(0.005)\end{array}$ & $\begin{array}{c}-0.024^{* * *} \\
(0.009)\end{array}$ & $\begin{array}{c}-0.047^{* * *} \\
(0.013)\end{array}$ & $\begin{array}{c}-0.055^{* * * *} \\
(0.013)\end{array}$ & $\begin{array}{c}-0.059^{* * *} \\
(0.014)\end{array}$ & $\begin{array}{c}-0.093^{* * *} \\
(0.012)\end{array}$ & $\begin{array}{c}-0.060^{* * *} \\
(0.015)\end{array}$ \\
\hline Foreign ownership & & $\begin{array}{l}0.080^{* * *} \\
(0.019)\end{array}$ & $\begin{array}{l}0.110^{* * *} \\
(0.029)\end{array}$ & $\begin{array}{c}0.070^{* * * *} \\
(0.020)\end{array}$ & $\begin{array}{c}0.109^{* * *} \\
(0.019)\end{array}$ & & $\begin{array}{c}0.104^{* * *} \\
(0.034)\end{array}$ & $\begin{array}{c}0.350^{* * *} * \\
(0.046)\end{array}$ & $\begin{array}{c}0.257^{* * * *} \\
(0.037)\end{array}$ & $\begin{array}{c}0.231^{* * * *} \\
(0.062)\end{array}$ \\
\hline ln Capital/Worker & $\begin{array}{l}-0.017^{* * *} \\
(0.005)\end{array}$ & $\begin{array}{l}-0.013 * * * \\
(0.005)\end{array}$ & $\begin{array}{l}-0.000 \\
(0.009)\end{array}$ & $\begin{array}{l}0.018^{* *} \\
(0.008)\end{array}$ & $\begin{array}{l}-0.008 \\
(0.006)\end{array}$ & $\begin{array}{l}-0.009 \\
(0.010)\end{array}$ & $\begin{array}{l}-0.015 \\
(0.012)\end{array}$ & $\begin{array}{l}-0.016 \\
(0.014)\end{array}$ & $\begin{array}{l}-0.015 \\
(0.013)\end{array}$ & $\begin{array}{c}0.003 \\
(0.022)\end{array}$ \\
\hline ln Skilled/Worker & $\begin{array}{l}-0.073 * * * \\
(0.017)\end{array}$ & $\begin{array}{c}-0.069 * * * \\
(0.014)\end{array}$ & $\begin{array}{c}-0.073^{* * *} \\
(0.019)\end{array}$ & $\begin{array}{l}-0.045^{* * *} \\
(0.017)\end{array}$ & $\begin{array}{c}-0.059^{* * *} * \\
(0.015)\end{array}$ & $\begin{array}{c}0.012 \\
(0.025)\end{array}$ & $\begin{array}{l}-0.014 \\
(0.027)\end{array}$ & $\begin{array}{c}-0.028 \\
(0.026)\end{array}$ & $\begin{array}{c}0.015 \\
(0.029)\end{array}$ & $\begin{array}{c}-0.032 \\
(0.038)\end{array}$ \\
\hline ln R\&D Sales & $\begin{array}{l}-0.003 \\
(0.003)\end{array}$ & $\begin{array}{c}-0.009 * * * \\
(0.003)\end{array}$ & $\begin{array}{c}-0.010^{* * *} \\
(0.003)\end{array}$ & $\begin{array}{c}-0.004 \\
(0.003)\end{array}$ & $\begin{array}{c}-0.010^{*} \\
(0.005)\end{array}$ & $\begin{array}{c}0.004 \\
(0.005)\end{array}$ & $\begin{array}{c}0.024^{* * *} * \\
(0.006)\end{array}$ & $\begin{array}{c}0.003 \\
(0.005)\end{array}$ & $\begin{array}{l}-0.003 \\
(0.007)\end{array}$ & $\begin{array}{c}0.008 \\
(0.007)\end{array}$ \\
\hline Nunn measure & $\begin{array}{c}0.127^{* * *} * \\
(0.027)\end{array}$ & $\begin{array}{c}0.117^{* * *} \\
(0.025)\end{array}$ & $\begin{array}{c}0.133^{* * * *} \\
(0.039)\end{array}$ & $\begin{array}{c}0.067^{* *} \\
(0.027)\end{array}$ & $\begin{array}{c}0.137^{* * *} \\
(0.046)\end{array}$ & $\begin{array}{c}0.008 \\
(0.063)\end{array}$ & $\begin{array}{l}-0.035 \\
(0.073)\end{array}$ & $\begin{array}{l}-0.023 \\
(0.098)\end{array}$ & $\begin{array}{l}-0.073 \\
(0.072)\end{array}$ & $\begin{array}{c}0.044 \\
(0.079)\end{array}$ \\
\hline ln demand elasticity & $\begin{array}{l}0.008^{*} \\
(0.005)\end{array}$ & $\begin{array}{c}0.006 \\
(0.005) \\
\end{array}$ & $\begin{array}{l}0.014^{*} \\
(0.007)\end{array}$ & $\begin{array}{c}0.000 \\
(0.004) \\
\end{array}$ & $\begin{array}{c}0.006^{*} \\
(0.003)\end{array}$ & $\begin{array}{l}-0.010 \\
(0.008) \\
\end{array}$ & $\begin{array}{l}-0.009 \\
(0.010) \\
\end{array}$ & $\begin{array}{l}-0.002 \\
(0.011) \\
\end{array}$ & $\begin{array}{l}-0.005 \\
(0.008) \\
\end{array}$ & $\begin{array}{l}-0.006 \\
(0.009) \\
\end{array}$ \\
\hline Observations & 809 & 765 & 509 & 1,004 & 1,004 & 809 & 765 & 509 & 1,004 & 1,004 \\
\hline$R^{2}$ & 0.093 & 0.123 & 0.108 & 0.360 & 0.142 & 0.025 & 0.057 & 0.127 & 0.303 & 0.070 \\
\hline
\end{tabular}

fees and/or supplied equipments on the overall number of transactions within a HS6 product. In column 6-10, the dependent variable is the

share of long-term collaborations. Robust standard-errors in brackets.

Table 10: The impact of cost dispersion - robustness checks (II)

\begin{tabular}{|c|c|c|c|c|c|c|c|c|c|c|}
\hline $\begin{array}{l}\text { Construction of } \\
\text { unit value } \mathrm{SD}\end{array}$ & $\begin{array}{c}\text { No } \\
\text { processing }\end{array}$ & $\begin{array}{l}\text { Only } \\
\text { LTC }\end{array}$ & $\begin{array}{c}\text { Japan } \\
\text { unit value } \mathrm{SD}\end{array}$ & $\begin{array}{c}\text { Japanese } \\
\text { exports }\end{array}$ & $\begin{array}{c}\text { Chinese } \\
\text { sales }\end{array}$ & $\begin{array}{c}\text { No } \\
\text { processing }\end{array}$ & $\begin{array}{l}\text { Only } \\
\text { LTC }\end{array}$ & $\begin{array}{c}\text { Japan } \\
\text { unit value } \mathrm{SD}\end{array}$ & $\begin{array}{l}\text { Japanese } \\
\text { exports }\end{array}$ & $\begin{array}{c}\text { Chinese } \\
\text { sales }\end{array}$ \\
\hline Dependent variable: & \multicolumn{5}{|c|}{$\begin{array}{c}\text { Share with fixed-fees } \\
\text { and/or supplied equipments }\end{array}$} & \multicolumn{5}{|c|}{$\begin{array}{c}\text { Share of long-term } \\
\text { collaborations }\end{array}$} \\
\hline Unit value SD & $\begin{array}{c}-0.021 * * * \\
(0.004)\end{array}$ & $\begin{array}{l}-0.025^{* * *} \\
(0.005)\end{array}$ & $\begin{array}{c}-0.025^{* * *} \\
(0.005)\end{array}$ & $\begin{array}{c}-0.063^{* * *} \\
(0.009)\end{array}$ & $\begin{array}{l}-0.013^{*} \\
(0.007)\end{array}$ & $\begin{array}{c}-0.062^{* * *} \\
(0.010)\end{array}$ & $\begin{array}{c}-0.050^{* * *} \\
(0.011)\end{array}$ & $\begin{array}{c}-0.051^{* * *} \\
(0.010)\end{array}$ & $\begin{array}{c}-0.078^{* * *} \\
(0.012)\end{array}$ & $\begin{array}{l}-0.006 \\
(0.015)\end{array}$ \\
\hline Foreign ownership & $\begin{array}{c}0.109^{* * * *} \\
(0.016)\end{array}$ & $\begin{array}{c}0.108^{* * *} \\
(0.016)\end{array}$ & $\begin{array}{c}0.109^{* * *} \\
(0.016)\end{array}$ & $\begin{array}{c}0.342^{* * *} \\
(0.028)\end{array}$ & $\begin{array}{c}0.102^{* * * *} \\
(0.019)\end{array}$ & $\begin{array}{c}0.237^{* * *} \\
(0.034)\end{array}$ & $\begin{array}{c}0.221 * * * \\
(0.035)\end{array}$ & $\begin{array}{c}0.225^{* * * *} \\
(0.033)\end{array}$ & $\begin{array}{c}0.188^{* * *} \\
(0.028)\end{array}$ & $\begin{array}{c}0.164 * * * \\
(0.040)\end{array}$ \\
\hline ln Capital/Worker & $\begin{array}{c}-0.008^{* *} \\
(0.004)\end{array}$ & $\begin{array}{c}-0.008^{* *} \\
(0.004)\end{array}$ & $\begin{array}{c}-0.009^{* *} \\
(0.004)\end{array}$ & $\begin{array}{l}-0.019^{* * *} * \\
(0.006)\end{array}$ & $\begin{array}{c}-0.018^{* * *} \\
(0.004)\end{array}$ & $\begin{array}{c}0.004 \\
(0.010)\end{array}$ & $\begin{array}{c}0.002 \\
(0.010)\end{array}$ & $\begin{array}{c}0.001 \\
(0.010)\end{array}$ & $\begin{array}{c}0.041^{* * *} \\
(0.011)\end{array}$ & $\begin{array}{l}-0.021^{*} \\
(0.012)\end{array}$ \\
\hline ln Skilled/Worker & $\begin{array}{c}-0.058^{* * *} \\
(0.011)\end{array}$ & $\begin{array}{c}-0.060^{* * *} \\
(0.011)\end{array}$ & $\begin{array}{c}-0.057^{* * *} * \\
(0.011)\end{array}$ & $\begin{array}{c}-0.128^{* * *} \\
(0.021)\end{array}$ & $\begin{array}{c}-0.043^{* * *} \\
(0.010)\end{array}$ & $\begin{array}{l}-0.035 \\
(0.022)\end{array}$ & $\begin{array}{l}-0.024 \\
(0.022)\end{array}$ & $\begin{array}{l}-0.020 \\
(0.022)\end{array}$ & $\begin{array}{c}-0.117^{* * *} \\
(0.029)\end{array}$ & $\begin{array}{c}0.003 \\
(0.024)\end{array}$ \\
\hline ln R\&D Sales & $\begin{array}{c}-0.010^{* * *} \\
(0.002)\end{array}$ & $\begin{array}{c}-0.010^{* * *} \\
(0.002)\end{array}$ & $\begin{array}{c}-0.009^{* * *} * \\
(0.002)\end{array}$ & $\begin{array}{c}-0.027 * * * \\
(0.003)\end{array}$ & $\begin{array}{c}-0.013 * * * \\
(0.002)\end{array}$ & $\begin{array}{l}0.008^{*} \\
(0.004)\end{array}$ & $\begin{array}{l}0.008^{*} \\
(0.004)\end{array}$ & $\begin{array}{c}0.009 * * \\
(0.004)\end{array}$ & $\begin{array}{c}0.008 \\
(0.005)\end{array}$ & $\begin{array}{c}0.008 \\
(0.005)\end{array}$ \\
\hline Nunn measure & $\begin{array}{c}0.136^{* * *} * \\
(0.020)\end{array}$ & $\begin{array}{c}0.136^{* * *} \\
(0.021)\end{array}$ & $\begin{array}{c}0.141 * * * \\
(0.020)\end{array}$ & $\begin{array}{c}0.246^{* * *} * \\
(0.032)\end{array}$ & $\begin{array}{c}0.130^{* * *} \\
(0.022)\end{array}$ & $\begin{array}{c}0.043 \\
(0.058)\end{array}$ & $\begin{array}{c}0.041 \\
(0.060)\end{array}$ & $\begin{array}{c}0.051 \\
(0.059)\end{array}$ & $\begin{array}{c}-0.124^{* *} \\
(0.060)\end{array}$ & $\begin{array}{c}0.020 \\
(0.072)\end{array}$ \\
\hline ln elasticity & $\begin{array}{l}0.006^{*} \\
(0.004)\end{array}$ & $\begin{array}{c}0.006 \\
(0.004)\end{array}$ & $\begin{array}{c}0.005 \\
(0.004)\end{array}$ & $\begin{array}{c}0.024^{* * *} * \\
(0.007)\end{array}$ & $\begin{array}{c}0.010^{* *} \\
(0.004)\end{array}$ & $\begin{array}{l}-0.006 \\
(0.008)\end{array}$ & $\begin{array}{l}-0.005 \\
(0.008)\end{array}$ & $\begin{array}{c}-0.006 \\
(0.007)\end{array}$ & $\begin{array}{c}-0.007 \\
(0.009)\end{array}$ & $\begin{array}{c}0.001 \\
(0.009)\end{array}$ \\
\hline Observations & 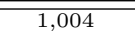 & 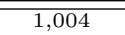 & 1,004 & 860 & 7440 & 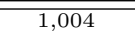 & 1,004 & 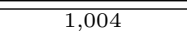 & 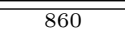 & 740 \\
\hline$R^{2}$ & 0.137 & 0.143 & 0.150 & 0.401 & 0.183 & 0.073 & 0.060 & 0.068 & 0.117 & 0.039 \\
\hline
\end{tabular}

share of long-term collaborations. Robust standard-errors in bractions

Robustness checks. In Table 9 we first conduct the same robustness checks as in Table 7 above and find that our main coefficients remain very stable and highly statistically significant in all specifications. Table 10 then considers additional robustness checks, in particular with respect to the construction of our cost dispersion measure, and with respect to the destination market for the Chinese exports.

\footnotetext{
${ }^{27}$ To save space, we only present results for the narrower proxy for RCs, namely processing agreement with fixed-fees and/or supplied equipments. Very similar results are obtained when using the wider RC proxy.
} 
First, in columns 1 and 6 of Table 7 we exclude all transactions with processing arrangements when constructing our dispersion variable. Hence, it becomes the standarddeviation of the log of the unit-value of transactions using ordinary trade only. We do so, since one might worry that our baseline measure captures differences in pricing rules associated with processing arrangements, because the duration of the transactions and the type of arrangement could both impact on the level of investments and, ultimately, on the unit values. Yet, columns 1 and 6 show that all results remain unchanged.

Second, we exclude all short-term transactions (less than 3 years) when constructing the dispersion, as those may also be priced differently which in turn could affect the unit values. Yet again, columns 2 and 7 yield very similar results as before.

Third, in columns 3 and 8 , we use the unit values of export transactions to Japan instead of the US to construct the cost dispersion across Chinese exporters. We choose Japan as it is the second main destination of Chinese exports after the US (besides HongKong and Macao). In addition, it has a similar level of contracting environment, which makes the two countries comparable in this sense. It turns out that the results remain very similar also when using this alternative proxy for product-level wide cost dispersion.

In our fourth robustness check, we use the export transactions to Japan to build our dependent variables (RC and LTC share), while using the transactions in the US market to build the dispersion measure. The results in column 4 and 9 are again very similar and the negative correlations remain highly significant. Our findings thus do not seem to be specific to US-China trade, but also apply to Chinese exports to other destinations.

In our last exercise we experiment with the use of firms' sales data to proxy for cost dispersion, similar as in Helpman et al (2004) and Yeaple (2006). More specifically, Nunn and Trefler (2013) provide information on the standard deviation of Chinese firms' sales at the HS6-digit level based on plant sales from the Orbis database, and we consider these data as our alternative proxy. Column 5 and 10 of Table 10 present the correlations of this sales dispersion with the share of RCs and LTCs, respectively. The coefficients remain negative, and in the former case significant at the $10 \%$ level. In the latter case the estimate becomes insignificant, however, which likely reflects the fact that this information is only available for fewer HS6 products so that the coefficient is estimated with less precision.

Overall, we obtain empirical results in Tables 8-10 that are firmly in line with Proposition 3 of our theoretical model. In particular, we find that higher cost dispersion across all Chinese firms exporting a particular product is negatively correlated with the share of LTCs, and with the share of RCs in that product category. In the light of our model, we may put forward one explanation for this pattern in the data: US headquarter corporations have an incentive to search harder when there is more heterogeneity across potential suppliers in China, and this higher search propensity postpones the formation of relational contracts as US firms have not yet found their ideal match.

\section{Conclusion}

In this paper, we have developed a dynamic property rights model of global sourcing where a domestic headquarter seeks to obtain an intermediate input from a foreign input 
supplier. Both, the specific foreign partner and the mode of play with him are endogenously determined in our model, and we have shown that the option to re-match crucially affects the timing when an efficient relational contract can be implemented. In particular, our model shows that there is a positive causal relationship between match durations (LTCs) and the stability of relational contracts (RCs). This key prediction of our model is empirically supported in the context of US input sourcing from China. The data show that more enduring export transactions from China are more likely to involve elements of relational contracting, which we have captured by particular types of processing trade arrangements. Furthermore, the data also confirm our theoretical prediction that more cost dispersion is negatively associated with match durations and relational contracts.

Our model is simple and can be extended in various directions. For example, we have focussed on the decision of one single headquarter firm and assumed that potential suppliers are abundantly available. While this assumption seems plausible on average in the context of US input sourcing from China, there are also cases with large and powerful suppliers (e.g. Foxconn) which have good outside options and bargaining power, and which actively seek to collaborate with the best possible headquarter firms. Such scenarios could be captured in a model with heterogeneity on both sides, and with assortative matching of headquarters and suppliers. However, our key result - the positive causal effect of match durations on relational contracting - arises already in our simpler environment.

On the empirical side, one has to deal with the fact that match-specific contractual arrangements between a buyer and a supplier are often tacit and implicit, and thus, by their very nature unobservable. Existing work on relational contracts has tackled this difficulty in detailed case studies about particular industries in developing countries. In this paper, we have taken a different avenue and considered all Chinese manufacturing exports in a particular time frame, and worked with proxies for relational contracts that capture - in our view - the essence of such trust-based cooperative arrangements fairly well. This approach based on representative panel data by the Chinese Customs authority might open the door for many further studies, especially if it can be matched with the Customs data of further countries.

\section{References}

[1] Abreu, D. On the Theory of Infinitely Repeated Games with Discounting. Econometrica 56, 2 (1988), 383-396.

[2] Aeberhardt, R., Buono, I., and Fadinger, H. Learning, Incomplete Contracts and Export Dynamics: Theory and Evidence from French Firms. European Economic Review 68 (2014), 219-249.

[3] Antràs, P. Firms, Contracts, and Trade Structure. The Quarterly Journal of Economics 118, 4 (2003).

[4] Antràs, P. Global Production: Firms, Contracts and Trade Structure. 2015. 
[5] Antràs, P., and Costinot, A. Intermediated Trade. The Quarterly Journal of Economics 126 (2011), 1319-1374.

[6] Antràs, P., And Helpman, E. Global Sourcing. Journal of Political Economy 112, 3 (2004), 552-580.

[7] Araujo, L., Mion, G., and Ornelas, E. Institutions and Export Dynamics. Journal of International Economics 98 (2016), 2-20.

[8] Baker, G., Gibbons, R., And Murphy, K. J. Relational Contracts and the Theory of the Firm. The Quarterly Journal of Economics 117, 1 (2002), 39-84.

[9] Bernard, A. B., Moxnes, A., and Ulltveit-Moe, K. H. Two-Sided Heterogeneity and Trade. Working Paper 20136, National Bureau of Economic Research, May 2014.

[10] Besedeš, T. A Search Cost Perspective on Formation and Duration of Trade. Review of International Economics 16, 5 (2008), 835-849.

[11] BoArd, S. Relational Contracts and the Value of Loyalty. American Economic Review 101, 7 (2011), 3349-67.

[12] Broda, C., And Weinstein, D. E. Globalization and the Gains from Variety. The Quarterly Journal of Economics 121, 2 (2006), 541-585.

[13] Burdett, K. A Theory of Employee Job Search and Quit Rates. The American Economic Review 68, 1 (1978), 212-220.

[14] Cajal-Grossi, J. Searching for Trade Patterns in Developing Countries: Testing Firms in the 'Fast Fashion' Industry. Mimeo, University of Warwick, 2016.

[15] Carballo, J., Ottaniano, G., and Volpe-Martincus, C. The Buyer Margins of Firms' Exports. Discussion Paper 1234, CEP, 2013.

[16] Corts, K. S., And Singh, J. The Effect of Repeated Interaction on Contract Choice: Evidence from Offshore Drilling. Journal of Law, Economics, and Organization 20, 1 (2004), 230-260.

[17] Eaton, J., Eslava, M., Jinkins, D., Krizan, C. J., And Tybout, J. A Search and Learning Model of Export Dynamics. Working Paper, 2014.

[18] Egan, M. L., And Mody, A. Buyer-Seller Links in Export Development. World Development 20, 3 (1992), 321-334.

[19] Feenstra, R. C., And Hanson, G. H. Ownership and Control in Outsourcing to China: Estimating the Property-Rights Theory of the Firm. The Quarterly Journal of Economics 120, 2 (2005), 729-761. 
[20] Fernandes, A. P., And Tang, H. Determinants of Vertical Integration in Export Processing: Theory and Evidence from China. Journal of Development Economics 99, 2 (2012), $396-414$.

[21] Green, E. J., And Porter, R. H. Noncooperative Collusion under Imperfect Price Information. Econometrica 52, 1 (1984), 87-100.

[22] Grossman, S. J., And Hart, O. D. The Costs and Benefits of Ownership: A Theory of Vertical and Lateral Integration. The Journal of Political Economy 94, 4 (1986), 691-719.

[23] Haag, M., and Lagunoff, R. On the Size and Structure of Group Cooperation. Journal of Economic Theory 135 (2007), 68-89.

[24] Harrington, J. E. Collusion Among Asymmetric Firms: The Case of Different Discount Factors. International Journal of Industrial Organization 7, 2 (1989), 289307.

[25] Hart, O. D., And Moore, J. Property Rights and the Nature of the Firm. Journal of Political Economy 98, 6 (1990), 1119-58.

[26] Helpman, E., Melitz, M. J., and Yeaple, S. R. Export versus FDI with Heterogeneous Firms. The American Economic Review 94, 1 (2004), 300-316.

[27] Johnson, R. C., And Noguera, G. Accounting for Intermediates: Production Sharing and Trade in Value Added. Journal of International Economics 86, 2 (2012), 224-236.

[28] Kamal, F., And Tang, H. Relational Trade: Evidence from the United States. Mimeo, 2015.

[29] Kee, H. L., And Tang, H. Domestic Value Added in Exports: Theory and Firm Evidence from China. American Economic Review 106, 6 (2016), 1402-1436.

[30] Kukharskyy, B. Relational Contracts and Global Sourcing. Journal of International Economics 101 (2016), 123 - 147.

[31] Kukharskyy, B., and Pflüger, M. Time is On My Side: Relational Contracts and Aggregate Welfare. Mimeo, 2016.

[32] Lehrer, E., And Pauzner, A. Repeated Games with Differential Time Preferences. Econometrica 67, 2 (1999), 393-412.

[33] Macchiavello, R., and Morjaria, A. Competition and Relational Contracts: Evidence from Rwanda's Coffee Mills. Working Paper, 2014.

[34] Manova, K., And Yu, Z. How Firms Export: Processing vs. Ordinary Trade with Financial Frictions. Journal of International Economics 100 (2016), 120-137. 
[35] Manova, K., And Zhang, Z. Export Prices Across Firms and Destinations. The Quarterly Journal of Economics 127 (2012), 379-436.

[36] Melitz, M. J. The Impact of Trade on Intra-Industry Reallocations and Aggregate Industry Productivity. Econometrica 71, 6 (2003), 1695-1725.

[37] Melitz, M. J., And Redding, S. J. Heterogeneous Firms and Trade. Handbook of International Economics 4 (2014), 1-54.

[38] Monarch, R. It's Not You, It's Me: Breakups in U.S.-China Trade Relationships. Working paper, 2015.

[39] Nunn, N. Relationship-Specificity, Incomplete Contracts, and the Pattern of Trade. The Quarterly Journal of Economics 122, 2 (2007), 569-600.

[40] Nunn, N., And Trefler, D. Incomplete Contracts and the Boundaries of the Multinational Firm. Journal of Economic Behavior \&3 Organization 94, 1 (2013), $330-344$.

[41] RAUCH, J. E. Networks versus Markets in International Trade. Journal of International Economics 48, 1 (1999), 7-35.

[42] Rauch, J. E., And Watson, J. Starting Small in an Unfamiliar Environment. International Journal of Industrial Organization 21, 7 (2003), 1021-1042.

[43] Schwarz, C., And Suedekum, J. Global Sourcing of Complex Production Processes. Journal of International Economics 93 (2014), 123 - 139.

[44] Yeaple, S. Offshoring, Foreign Direct Investment, and the Structure of U.S. Trade. Journal of the European Economic Association 4, 2-3 (2006), 602-611. 


\section{APPENDIX}

\section{A Proof of Proposition 1}

We prove this Proposition in two steps. First, consider the special case where the headquarter and the supplier have a common discount factor $\delta_{H}=\delta_{M}=\delta$. In that case, we may rephrase Proposition 1 to state that the $\mathrm{RC}$ inducing first best investment levels $\left(h^{*}, m^{*}\right)$ can be supported as a SPNE of the repeated game for all

$$
\delta \geq \underline{\delta}(\alpha, \beta, \eta)
$$

with a corresponding optimal bonus payment $B^{*}(\delta)=m^{*} c_{m}+\left[\delta \pi_{M}^{N}+(1-\delta) \pi_{M}^{D}\right]$. To show this, use (IC-H') and (IC-M') to solve $B_{H}(\underline{\delta})=B_{M}(\underline{\delta})$ for $\underline{\delta}$. This yields $\underline{\delta}=\frac{\pi^{J F B}-\pi_{H}^{D}-\pi_{M}^{D}}{\pi_{H}^{N}+\pi_{M}^{N}-\pi_{H}^{D}-\pi_{M}^{D}}=\frac{\sum_{i} \pi_{i}^{D}-\pi^{J F B}}{\sum_{i} \pi_{i}^{D}-\sum_{i} \pi_{i}^{N}}$. Using $B^{*}(\delta)$ in (7), and comparing it to (5) and (9), it follows immediately that $\pi_{i}^{D}>\pi_{i}^{R C}>\pi_{i}^{N}>0$ for $i=H, M$. This ordering of payoffs implies $\sum_{i} \pi_{i}^{D}>\pi^{J F B}>\sum_{i} \pi_{i}^{N}$, and thus $\underline{\delta} \in(0,1)$. Plugging in the expressions for $\pi_{i}^{N}, \pi_{i}^{R C}$, and $\pi_{i}^{D}$ from (5), (7), and (9) yields the explicit expression for the critical discount factor $\underline{\delta}$ that solely depends on $\alpha, \beta$ and $\eta$, but not on $A, c_{h}, c_{m}$ or $\tau$ :

$$
\underline{\delta}(\alpha, \beta, \eta)=\frac{1-\alpha-(1-\alpha \eta) \beta^{\frac{1}{1-\alpha \eta}}-(1-\alpha(1-\alpha \eta))(1-\beta)^{\frac{1}{1-\alpha(1-\eta)}}}{(1-\alpha \eta)\left[\beta^{\frac{1-\alpha(1-\eta)}{1-\alpha}}(1-\beta)^{\frac{\alpha(1-\eta)}{1-\alpha}}-\beta^{\frac{1}{1-\alpha \eta}}\right]+(1-\alpha(1-\eta))\left[\beta^{\frac{\alpha \eta}{1-\alpha}}(1-\beta)^{\frac{1-\alpha \eta}{1-\alpha}}-(1-\beta)^{\frac{1}{1-\alpha(1-\eta)}}\right]} .
$$

Second, turning now to the case with heterogeneous discount factors $\left(\delta_{H} \neq \delta_{M}\right)$, we can rewrite the agents' incentive constraints as

$$
\begin{gathered}
\frac{1}{1-\delta_{M}}\left[B-m^{*} c_{m}\right] \geq \pi_{M}^{D}+\frac{\delta_{M}}{1-\delta_{M}} \pi_{M}^{N}, \\
\frac{1}{1-\delta_{H}}\left[R^{*}-h^{*} c_{h}-B\right] \geq \pi_{H}^{D}+\frac{\delta_{H}}{1-\delta_{H}} \pi_{H}^{N} .
\end{gathered}
$$

The firm will set the bonus $B$ such that (IC-M) binds with equality. Solving it for $B$ yields the optimal bonus payment, $B^{*}\left(\delta_{M}\right)=m^{*} c_{m}+\left[\delta_{M} \pi_{M}^{N}+\left(1-\delta_{M}\right) \pi_{M}^{D}\right]$. Inserting this into (IC-H) and rearranging gives

$$
\delta_{M}\left(\pi_{M}^{D}-\pi_{M}^{N}\right)+\delta_{H}\left(\pi_{H}^{D}-\pi_{H}^{N}\right) \geq \pi_{M}^{D}+\pi_{H}^{D}-\pi^{J F B},
$$

and dividing this expression by $\sum_{i}\left(\pi_{i}^{D}-\pi_{i}^{N}\right)$ we obtain condition (10) as stated above:

$$
\widetilde{\delta} \equiv \frac{\sum_{i} \delta_{i}\left(\pi_{i}^{D}-\pi_{i}^{N}\right)}{\sum_{i}\left(\pi_{i}^{D}-\pi_{i}^{N}\right)} \geq \frac{\sum_{i} \pi_{i}^{D}-\pi^{J F B}}{\sum_{i}\left(\pi_{i}^{D}-\pi_{i}^{N}\right)}=\underline{\delta}(\alpha, \beta, \eta)
$$

The RHS of this inequality is the same as for the case of homogeneous discount factors, i.e., the same critical level $\underline{\delta}$ applies as before. The LHS is a weighted average of $\delta_{H}$ and $\delta_{M}$, with weights given by $\left(\pi_{i}^{D}-\pi_{i}^{N}\right)$. Plugging in the terms from (5) and (9) we can rewrite the LHS as 
$\widetilde{\delta}\left(\delta_{H}, \delta_{M}, \alpha, \beta, \eta\right)=\frac{\delta_{H} \cdot \beta(1-\alpha \eta)\left[\beta^{\frac{\alpha \eta}{1-\alpha \eta}}-\hat{\beta}\right]+\delta_{M} \cdot(1-\beta)(1-\alpha(1-\eta))\left[(1-\beta)^{\frac{\alpha(1-\eta)}{1-\alpha(1-\eta)}}-\hat{\beta}\right]}{\beta(1-\alpha \eta)\left[\beta^{\frac{\alpha \eta}{1-\alpha \eta}}-\hat{\beta}\right]+(1-\beta)(1-\alpha(1-\eta))\left[(1-\beta)^{\frac{\alpha(1-\eta)}{1-\alpha(1-\eta)}}-\hat{\beta}\right]}$

where $\hat{\beta} \equiv\left(\beta^{\eta}(1-\beta)^{(1-\eta)}\right)^{\frac{\alpha}{1-\alpha}}$. Notice that $\widetilde{\delta}$ also does not depend on $A, c_{h}, c_{m}$ and $\tau$, and that $\widetilde{\delta}=\delta$ if $\delta_{H}=\delta_{M}=\delta$.

\section{B Preventing "cheat-and-run"}

To rule out "cheat-and-run" (CAR), the following condition must be satisfied to ensure that the firm stops deviating once it is matched to a low-cost supplier:

$$
\frac{1}{1-\delta_{H}} \pi_{H}^{R C, l} \geq E\left[\pi_{H}^{C A R} \mid c_{m}^{0}=c_{m}^{l}\right]
$$

Since low-cost suppliers are only found with probability $P$ in every round, the "cheatand-run" payoff can be computed by the following program:

$$
V_{0}=\pi_{H}^{D, l}-F+\delta_{H} P V_{0}+\delta_{H}(1-P) V_{1}, \quad V_{1}=\pi_{H}^{D, h}-F+\delta_{H} P V_{0}+\delta_{H}(1-P) V_{1},
$$

and solving for $V_{0}$ gives

$$
E\left[\pi_{H}^{C A R} \mid c_{m}^{0}=c_{m}^{l}\right]=\frac{1}{1-\delta_{H}}\left[\left(1-\delta_{H}(1-P)\right) \pi_{H}^{D, l}+\delta_{H}(1-P) \pi_{H}^{D, h}-F\right] .
$$

With this, we can rewrite condition (18) as follows:

$$
F \geq\left(1-\delta_{H}(1-P)\right) \pi_{H}^{D, l}+\delta_{H}(1-P) \pi_{H}^{D, h}-\pi_{H}^{R C, l}
$$

Since the RHS of (19) is increasing in $P$, "cheat-and-run" can be precluded for all $P$ by requiring the following sufficient condition:

$$
F>\pi_{H}^{D, l}-\pi_{H}^{R C, l} \equiv \widetilde{F}
$$

For consistency it is necessary to show that the lower bound $\widetilde{F}$ does not per se rule out search and re-matching for $c_{m}^{0}=c_{m}^{h}$ in the case of patient agents. For this, it is necessary to show that $\widetilde{F}<\bar{F}^{2}(\widetilde{\delta})$ can hold for every relevant patience level $\delta_{H}$ such that $\widetilde{\delta} \in(\underline{\delta}, 1)$. In the following we derive a sufficient condition for $\widetilde{F}<\bar{F}^{2}(\underline{\delta})$, which then automatically implies $\widetilde{F}<\bar{F}^{2}(\widetilde{\delta})$ since $\bar{F}^{2}(\widetilde{\delta})$ is increasing in $\widetilde{\delta}$. Rearranging $\widetilde{F}<\bar{F}^{2}(\underline{\delta})$ gives:

$$
P>\frac{(1-\underline{\delta})\left(\pi_{H}^{D, l}-\pi_{H}^{R C, l}(\underline{\delta})+\pi_{H}^{R C, h}(\underline{\delta})-\pi_{H}^{N, h}\right)}{\underline{\delta}\left(\pi_{H}^{R C, l}(\underline{\delta})-\pi_{H}^{R C, h}(\underline{\delta})\right)} \equiv \widetilde{P}
$$

$\pi_{H}^{R C}(\underline{\delta})$ denotes RC-profits at the critical discount factor. We need $\widetilde{P} \in(0,1)$ for $G\left(c_{m}\right)$ 
to be well-defined. Obviously $\widetilde{P}>0$. Assuming $\widetilde{P}<1$ and rearranging we get:

$$
(1-\underline{\delta})\left[\pi_{H}^{D, l}-\pi_{H}^{N, h}\right]<\pi_{H}^{R C, l}-\pi_{H}^{R C, h} \Leftrightarrow \quad(1-\underline{\delta}) \pi_{H}^{D, l}-\pi_{H}^{R C, l}<(1-\underline{\delta}) \pi_{H}^{N, h}-\pi_{H}^{R C, h}
$$

Notice that both RHS and LHS of this last inequality are negative if the sufficient condition holds. Factorizing $\tau c_{m}^{l}$ from the LHS, and $\tau c_{m}^{h}$ from the RHS, respectively, we can rewrite this sufficient condition in the following form:

$$
\frac{c_{m}^{h}}{c_{m}^{l}}>C(\alpha, \beta, \eta)
$$

where $C$ is a positive term that depends on $\alpha, \beta$, and $\eta$. Summing up, if the cost dispersion $c_{m}^{h} / c_{m}^{l}$ is sufficiently large, condition (23) is satisfied and we have $\widetilde{F}<\bar{F}^{2}(\widetilde{\delta})$. Notice that this does not automatically ensure $\widetilde{F}<\bar{F}^{1}(\widetilde{\delta})$. However, even if $\bar{F}^{1}(\widetilde{\delta})<\widetilde{F}$, this does not alter the validity of our prediction of a positive effect of match duration on RC propensity, since impatient agents never engage in RCs. 